\title{
An Eight Component Decision-Making Model for Problem Gambling:A Systems Approach to Stimulate Integrative Research
}

\author{
David Nussbaum • Kimia Honarmand • Richard Govoni • \\ Martina Kalahani-Bargis • Stephanie Bass $\cdot$ Xinqun Ni • \\ Kaitlyn LaForge • Andrea Burden • Kristoffer Romero • \\ Sonya Basarke $\cdot$ Christine Courbasson $\cdot$ Wade Deamond
}

Published online: 30 December 2010

(C) The Author(s) 2010. This article is published with open access at Springerlink.com

\begin{abstract}
Problem Gambling (PG) represents a serious problem for affected individuals, their families and society in general. Previous approaches to understanding PG have been confined to only a subset of the psychobiological factors influencing PG. We present a model that attempts to integrate potential causal factors across levels of organization, providing empirical evidence from the vast literature on PG and complimentary literatures in decision-making and addiction. The model posits that components are arranged systematically to bias decisions in favor of either immediately approaching or avoiding targets affording the opportunity for immediate reward. Dopamine, Testosterone and Endogenous Opioids favor immediate approach, while Serotonin and Cortisol favor inhibition. Glutamate is involved in associative learning between stimuli and promotes the approach
\end{abstract}

D. Nussbaum $(\bowtie) \cdot$ M. Kalahani-Bargis

Department of Psychology, University of Toronto Scarborough, SW414 1265 Military Trail,

Toronto, ON M1C 1A4, Canada

e-mail: dnussbaum@utsc.utoronto.ca

D. Nussbaum

Ontario Shores Centre for Mental Health Sciences, 700 Gordon Street, Whitby, ON L1N 5S9, Canada

K. Honarmand

Michael G. DeGroote School of Medicine, McMaster University, 1200 Main St. W., Hamilton, ON L8N 3Z5, Canada

e-mail:kimia0221@gmail.com

R. Govoni

Department of Psychology, University of Windsor, Windsor, ON N9B 3P4, Canada

S. Bass · K. Romero

Graduate Department of Psychology, University of Toronto, 151 St. George St., Toronto, ON, Canada e-mail: slsbass@gmail.com

K. Romero

e-mail: kris.romero@utoronto.ca

X. Ni · C. Courbasson

Centre for Addiction and Mental Health, 250 College Street, Toronto, ON M5T 1R8, Canada 
response through its link to the DA reward system. GABA functions to monitor performance and curb impulsive decision-making. Finally, while very high levels of Norepinephrine can induce arousal to an extent that is detrimental to sound decision-making, the reactivity of the Norepinephrine system and its effects of Cortisol levels can shift the focus towards long-term consequences, thereby inhibiting impulsive decisions. Empirical evidence is provided showing the effects of each component on PG and decision-making across behavioural, neuropsychological, functional neuroimaging and genetic levels. Last, an effect size analysis of the growing pharmacotherapy literature is presented. It is hoped that this model will stimulate multi-level research to solidify our comprehension of biased decision-making in PG and suggest pharmacological and psychological approaches to treatment.

Keywords Problem gambling · Decision-making - Impulsivity · Psychopharmacology · Impulse control disorders

While occasional social gambling is a pleasant diversion for most, Problem Gambling (PG) reflects loss of control over gambling that persists despite often daunting negative consequences (Goudriaan et al. 2005) The lifetime prevalence of PG in the United States is 2.3\% (Kessler et al. 2008) while in Canada a similar 2\% national prevalence rate was reported with individual provincial rates ranging between 1.5 and 2.9\% (Cox et al. 2005).

One can regard PG as a variant within the gambling behaviour spectrum. "Social Gamblers" exert reasonable control and limit their losses, perhaps considering the affordable costs as entertainment dollars that might have otherwise been spent on a professional sports match or the theatre at comparable expense. Others show less ability to regulate their gambling behaviour. Additionally, gambling takes many forms from the typically benign government sponsored lotteries and sports betting lines to more insidious casinos with their array of slot machines, roulette wheels and poker tables. Animal races furnish a different form of gambling activity and technology has provided widespread electronic video gambling opportunities. Along with the range of gambling activities, individuals display either a continuum or a set of discrete difficulties in dealing with their desires to gamble. Significant severity is sometimes denoted by designating an individual a

K. LaForge

Graduate Program in Psychology, Brock University, 500 Glenridge Ave., St. Catharines,

ON L2S 3A1, Canada

e-mail: kaiblyn@hotmail.com

\author{
A. Burden \\ Leslie Dan Faculty of Pharmacy, University of Toronto, 144 College St., Toronto, \\ ON M5S 3M2, Canada \\ e-mail: a.burden@utoronto.ca \\ S. Basarke \\ Graduate Program in Psychology, Ryerson University, 350 Victoria Street, Toronto, \\ ON M5B 2K3, Canada \\ e-mail: sbasarke@psych.ryerson.ca \\ W. Deamond \\ Graduate Department of Psychology, Yorkville University, 1149 Smythe St, Fredericton, \\ NB E3B 3H4, Canada \\ e-mail:w.123.d@sympatico.ca
}


"Gambling Addict" if gambling becomes the major focus of their existence. Pathological Gambling, formerly defined as a Disorder of Impulse Control according to DSM-IV (APA 1994), has been reclassified under "Addiction and Related Disorders" in the forthcoming DSM-V. The term PG has been used in a perhaps a less judgmental fashion to describe a repetitive pattern of gambling that leads to serious destructive consequences and is beyond voluntary control (Skitch and Hodgins 2004).

Given the multiplicity of gambling activities and the diversity of individuals who experience difficulties with gambling, it is not surprising that scholars examining the complex intersection between activities and individuals have developed different frameworks for describing and explaining putative core difficulties, with some researchers presenting alternate models crossing the various domains. Paralleling domain foci in the broad behavioral sciences, in a vast and growing literature, various authors have focused on dysfunctional aspects of cognition (Toneatto 1999; see Toplak et al. 2007, for a recent summary and innovative model), mathematical models based on rational cost/benefit considerations (Fennema and van Assen 1998), deficient emotional cues and coping with emotional difficulties (e.g., Bechara et al. 1994; Nelson et al. 2009; Shead and Hodgins 2009; Stewart et al. 2008), motivational dysregulation, especially with an over-focus on reward (e.g., Bechara et al. 2002; Goudriaan et al. 2004), psychopathology focusing on personality, impulsivity and compulsivity (e.g., Blazszczynski et al. 1997; Blazszczynski and Steel 1998; Skitch and Hodgins 2004; Westphal 2008) and neurobiological aspects of PG and related decision-making characteristics (e.g., Cavendini et al. 2002; McClure et al. 2004.) This list is illustrative but not exhaustive.

Broader models highlight the multifaceted nature of PG, providing access to motivational and emotional processes that contribute significantly to often unsound DM intrinsic to PG. Engel's (1977) Biopsychosocial (BPS) model recognizes that individuals inhabit a complex world and functional and dysfunctional behaviour likely reflect numerous internal and external factors. The BSP model organizes potential factors into three interacting sectors: social, psychological and biological.

As Engel noted such an approach "provides a blueprint for research, a framework for teaching and a design for action in the real world of health care" (Griffiths and Delfabbro 2001). Williams et al. (2007) use the BPS model as an organizing structure for understanding the etiology of PG and its ultimate consequences. They propose a sequence of four stages in the development of PG: (1) Genetic inheritance, (2) environmental initiation, (3) operant and classical conditioning, and (4) negative social and health consequences (Williams et al. 2007).

Sharpe (2004) has recently utilized the BPS model to reformulate a cognitive-psychobiological model of PG. Sharpe's model posits that genetic vulnerability in the presence of negative early environments translates into impaired cognitive choices operationalized by negative synergistic interactions involving the dopaminergic or reward system and the serotonergic or inhibitory system. Negative early environments favour immediacy, impulsivity and PG. The model suggests that these psychological and biological vulnerabilities are especially sensitive to early gambling experiences such as early wins, imprinting cognitive biases and resulting in behavioral patterns being established. Sharpe also recognizes the contributions of stressful life circumstances to PG, but does not elaborate.

An extensive literature exists regarding experimental manipulation of factors that enhance or impair DM in conditions of uncertainty or risk, but a key issue in integrating this body of knowledge is: "the fragmented and insular nature of research programs. Despite token recognition of the complexity of gambling behaviour, most research has been rigidly confined to narrow areas of specialization (Griffiths and Delfabbro 2001)." 
In the last decade, innovative authors have amalgamated differing perspectives in more inclusive and hopefully more precise models. For example, Blazszczynski and Nower (2002) developed the "pathways model" with distinct behavioral conditioning, emotional vulnerability and antisocial impulsivity routes to explain how PG is initiated and maintained in different PG subtypes. Stewart and Zack (2008) have presented supportive evidence for three inter-correlated factors reflecting intrapersonal positive reinforcement, intrapersonal negative reinforcement and interpersonal positive reinforcement. Nower and Blazszczynski (2006) presented a broad descriptive model assimilating predisposing factors, individual differences, social milieu, cognitive characteristics and emotional coloring of contexts to explain impulsive DM in the PG context. Lee et al. (2008) recently identified three factors underlying pathological gambling in Korean casinos; emotional instability, reward sensitivity and need to express ones' self behaviorally. Emerging from these and other perspectives is the notion that different psychological and neurobiological forces operate in different individuals to drive PG. Perhaps this is best captured by Westphal (2008) when in summarizing the state of psychiatric literature on PG, writes:

Heterogeneity among pathological gamblers or confounding could be the factors contributing to the failures of the current conceptual models. New models such as multi-component or subtype models may be needed. (p. 602.)

The purpose of this paper is to suggest a comprehensive multi-component psychobiological model accommodating different aspects of the DM process with coherent subtypes emerging from sub-optimal functioning of individual components of an integrated and interacting system. Evidence for each component is provided at multiple levels of organization. This model should be considered provisional at this point and best used to generate research involving simultaneous measures of its components in different PG and comparison groups obtained during gambling-related tasks.

\section{A Psychobiological Model for Executive Function and Decision Making in Problem Gambling}

Figure 1 identifies the model components that individually and interactively bias motivational DM towards either immediate gratification (Approach-Reward) or inhibition (Stop-Consider) subsequently permitting cognitive appraisal. The two parallel systems are synergistically arranged. When all systems are functioning well, the individual is afforded the opportunity to weigh all information regarding temporally immediate and distal rewards and their relative magnitudes in line with the individual's immediate and longterm goals. However, when system components are over- or under-reactive to cues signaling availability of reward, the associated bias will result in unsound DM.

The diagram also loosely follows a time sequence beginning with perception of the potential source of immediate gratification and moving leftward with time. In the first instance, the ventral-tegmental accumbens (VTA) dopaminergic (DA) reward system is recruited and is potentially "controlled" by inhibitory frontal serotonergic (5-HT) neurons. The relative "rise-times" of activation of DA and 5-HT is critical here because if DA activation occurs very rapidly, the consumatory behaviour will be completed before the 5-HT "brake" can be applied. Subsequent inhibitory influences will be ineffective as the proverbial "horses will already have left the barn." Should a steeper 5-HT rise time preempt the DA system, the interrupted focus on gratification will allow for a rational consideration of the long-term consequences of the consumatory response and only when 


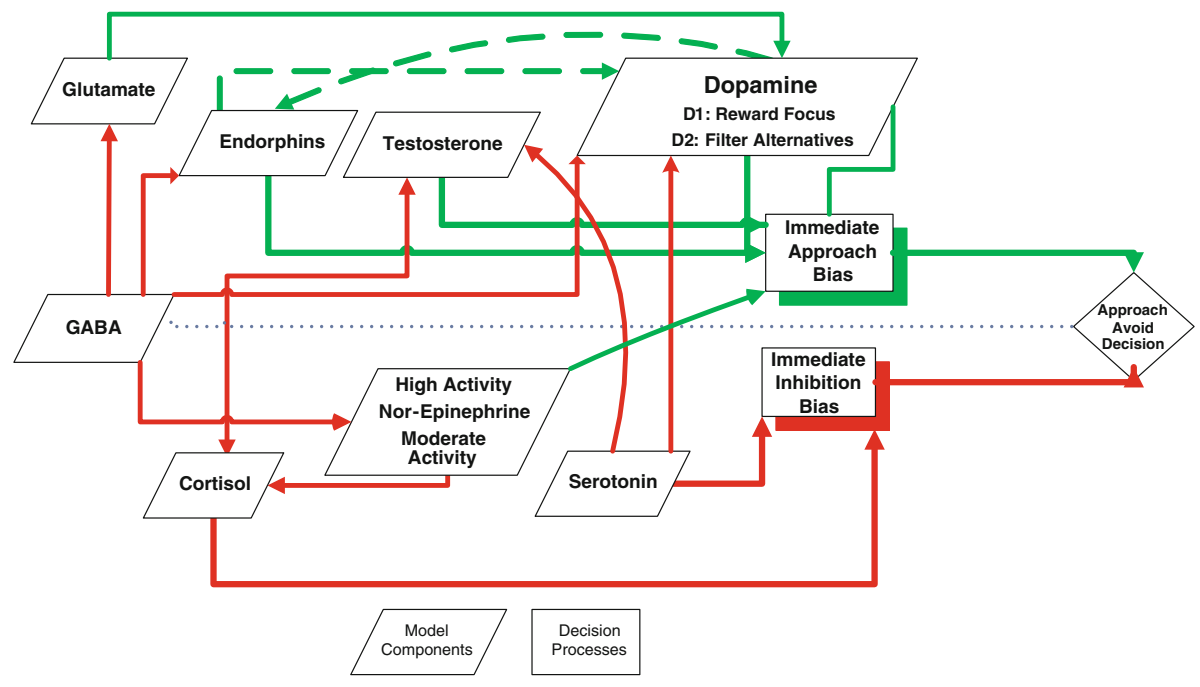

Kev:

Red indicates inhibitory pathway

Green indicates activation pathway

Dashed line indicates synergistic effects within Approach or Inhibition components. (See text for details)

Fig. 1 A central psychobiological model for decision-making in problem gambling

cognitively appropriate will consumatory behaviour occur. Such cognitive appraisal is likely governed by dorsolateral executive processes.

The second temporal stage reflects a more dispositional and perhaps slower acting propensity towards either approaching or avoiding potential sources of immediate gratification. Anxiety and stress, reflected initially by Nor-Epinephrine (NE) and if it persists, followed by Cortisol (C), have a general inhibitory effect, favouring avoidance of immediate reward choice. Testosterone provides the opposite longer-term and dispositional influence, essentially "energizing" approach responses. It is the ratio between the respective activation time-courses for these hormones rather than resting levels that is critical. The third "end stage" characterized by the "rush" experienced by problem gamblers when achieving a big "win" is associated with opioid receptors that are activated by DA activity and opposed by Gamma-Amino Butyric Acid (GABA). We suggest that one of the factors that distinguishes between individuals with PG and more severe gambling addictions (i.e., gambling becomes their total focus) has to do with the ease with which DA activity induces opioid production and utilization and the efficacy of the GABA inhibitory system in modulating the highly pleasurable opioid release. Hypothesized psychological functions for each model component are illustrated in Fig. 2.

\section{Development of and Rationale for the Model}

\section{Dopamine and Serotonin Components}

Our proposed model was stimulated by Vogel-Sprott's (1967) study on the effects of alcohol on DM. Alcohol caused reinstatement of responding for a small monetary reward despite re-establishment of previously inhibiting electric shock. Vogel-Sprott attributed the 


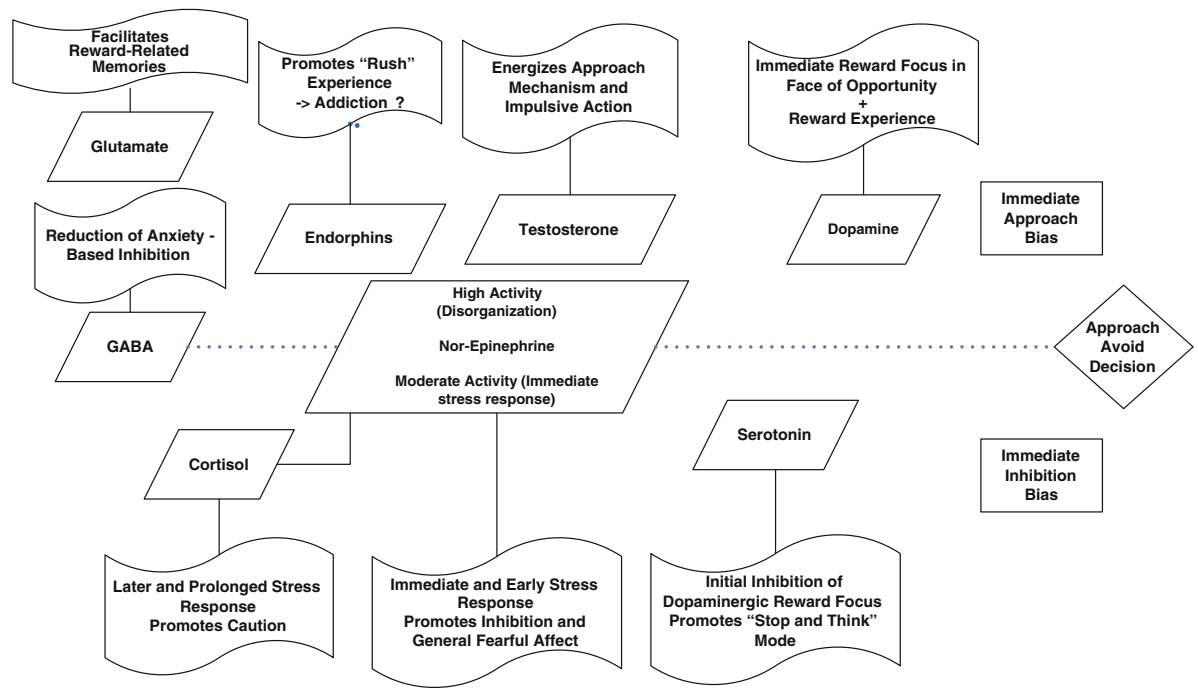

Fig. 2 Hypothesized psychological roles for individual decision-model components

initial reward-seeking behaviour to the dopaminergic VTA reward system, inhibited by the 5-HT reaction to the shock, leading to cessation of reward responding. However, alcohol's inhibition of 5-HT disinhibited the DA reward system, resulting in responding for reward and ignoring the previously inhibiting yoked shocks. While alternative explanations could be proposed, a subsequent conceptual replication with functional neuroimaging supported the original hypotheses (Vogel-Sprott et al. 2001). Further, a plethora of evidence suggests that the reinforcing properties of most drugs are derived from the surge of DA in the mesolimbic system (Rompre and Wise 1989). Although this paradigm does not speak to DM under conditions of risk specifically related to PG, it does suggest specific interactive brain mechanisms that could be biased in terms of focusing attention toward immediate rewards or negative consequences. Before describing the supporting literature, we describe a task that has been used extensively to examine "impulsive" DM in motivational contexts.

\section{Bechara's Iowa Gambling Task and Evidence of DA and 5-HT Decisional Antagonism}

The Iowa Gambling Task (IGT; Bechara et al. 1994) is a computerized test originally developed to identify faulty DM undetectable through existing cognitive tests, secondary to ventromedial prefrontal cortex (VMPC) damage. How the IGT works remains unsettled (Bass and Nussbaum 2010), but numerous studies suggest that individuals with PG show deficits in IGT performance (Petry 2001; Cavedini et al. 2002; Goudriaan et al. 2004). In the IGT, players choose a total of 100 cards individually from 4 decks under instructions to win as much money as possible. All choices result in "wins" but disadvantageous decks frequently provide large wins and occasional catastrophic losses, while advantageous decks provide modest gains but smaller losses. Successful play requires integration of fluctuating gain and loss patterns over succeeding trials to accumulate and maintain winnings.

One view is that success on the IGT depends on the relative biases between immediate and long-term reward focus, implying that impulsive decision-makers opt for immediate rather than long-term rewards. Pharmacological manipulation of DA levels using DA 
agonists and antagonists, result in enhanced and deteriorated IGT performance respectively, but only during the initial phase of the task (Blocks 1-4, each block consisting of 20 card selections; Bechara et al. 2001). Conversely, 5-HT agonists selectively enhanced Block 5 performance while 5-HT antagonists deteriorated Block 5 decisions exclusively (Bechara et al. 2001). Bechara et al. account for this double dissociation by noting that Blocks 1 through 4 require motivation to decipher the task and not inhibition. By the 80th trial, their sample had mastered the task and success in the last Block (20 trials) depends only on avoidance of the disadvantageous decks. Recent exposition of the negative reciprocal effects of DA and 5-HT on DM suggests that this transcends phylogeny and may be a basic "design feature" of the mammalian DM process (Daw et al. 2002).

\section{Genetic Evidence}

\section{Dopamine}

Genetic studies are helpful in establishing the roles of DA receptors in PG. Firstly, allelic variants of DA receptors (DRD2, DRD3, DRD4) are found at greater frequencies or present in different distributions in individuals with PG (Comings 1998; Kreek et al. 2005; da Silva Lobo et al. 2007). The DRD1 Dde1 allele is more prevalent in pathological gamblers with a comorbid diagnosis of either alcohol or drug dependence (Comings 1998; Comings et al. 1999). The dopamine D4 receptor gene (DRD4) exon III variable-numberof-tandem-repeats (VNTR) have also been associated with impulsive personality traits and PG (Comings et al. 1999). Comings and colleagues (2001) supported the significant associations between PG and the DRD2, DRD4 and the dopamine transporter gene (DAT). Da Silva Lobo et al. (2007) found that the T allele of DRD1-800T/C polymorphism showed a higher frequency in gamblers compared with sibling controls, but the other dopamine genes (DRD2, DRD3, DRD4, DRD5 and DAT) did not differentiate the groups (da Silva Lobo et al. 2007). The COMT rs4818 polymorphism, in a haploblock with the Val158Met polymorphism, seems to account for a greater variation of the COMT activity compared to Val158Met. In a sample of healthy males, individuals with the rs $4818 \mathrm{G} / \mathrm{G}$ genotype have strikingly better performance in the IGT compared to those with $\mathrm{G} / \mathrm{C}$ or $\mathrm{C} / \mathrm{C}$ genotypes (Roussos et al. 2008).

Other studies have reported an association between PG with allele 1 of the dopamine D2 receptor gene (DRD2), TaqIA polymorphism (Comings et al. 1996). It has also been found that differences in the distribution of the DRD2 polymorphism between problem gamblers with a variety of comorbid psychiatric conditions relative to those with no comorbid disorders (Ibanez et al. 2001). The gambling severity scores were positively and linearly related to the number of comorbid diagnoses. Comorbid diagnoses were in turn predicted by the presence of the $\mathrm{C} 4$ allele, which was present in $42 \%$ of gamblers with a lifetime history of comorbid disorders compared to $5.3 \%$ of gamblers without a history of comorbid disorders (Ibanez et al. 2001). Thus the DRD2 variant may represent a "general impulsivity factor" while the DRD3 and DRD4 alleles may bear a more specific association with PG.

\section{Serotonin}

The involvement of 5-HT in deficient impulse control and impulsive personality features has also been supported by genetic studies. A variant in the promoter region of the serotonin transporter gene (5-HTTLPR) was found to be significantly associated with PG in 
males with significantly higher frequencies of the short allele, but not in females (Perez et al. 1999). Tryptophan 2,3-dioxygenase (TDO2) is the rate-limiting enzyme for the breakdown of tryptophan, a serotonin precursor, to $\mathrm{N}$-formyl kenurenine. An intron $6 \mathrm{G}$ to $\mathrm{T}$ variant, associated with platelet serotonin levels, was significantly associated with PG but not with alcoholism (Comings et al. 2001; Comings et al. 1996). Comings et al. (2001) reported an association between the tryptophan hydroxylase gene (TH). Other studies have found that 5-HT1B knockout mice showed greater motor impulsivity (Brunner and Hen 1997).

Relationships exist between allelic polymorphisms in the Monoamine Oxidase A (MAO-A) and MAO-B genes and PG. Specifically, the MAO-B allele has been reportedly linked to more severe PG in males (Goudriaan et al. 2004), although this finding is not universal (de Castro et al. 2001). In addition, low MAO-A promoter gene function has been found to be related to PG in males (Ibanez et al. 2000; de Castro et al. 2001). These findings are consistent with the model's proposition linking 5-HT deficiency with inhibition deficits in PG.

\section{Evidence from Neuroimaging}

Much of the evidence for the involvement of the dopaminergic system in PG and impulsive DM comes from studies using neuroimaging to establish activity in the mesolimbic pathway. The mesolimbic DA pathway, which links the VTA to the striatum, specifically the nucleus accumbens of the striatum, has been shown in many studies to underlie the pleasurable feelings associated with reward and is heavily implicated in the neurobiological theories of addiction.

Greater activation of the cortico-striatal pathways, associated with reward anticipation, has been reported by several neuroimaging studies (Elliot et al. 2000; Abler et al. 2009). Elliot et al. (2000) used fMRI to measure neural responses associated with accumulating rewards as opposed to absolute reward values. Progressive increases in levels of reward (a winning streak) activated the pallidum, anteroventral thalamus and subgenual cingulate, all of which receive projections from striatal and limbic regions implicated in reward and punishment sensitivity (Alexander et al. 1986). Total reward values influenced activation of the midbrain and ventral striatal DA regions, reconfirming the role of DA pathways in reward-sensitivity. An fMRI study of patients treated with DA receptor agonists (to treat restless leg syndrome) during the IGT showed that reward expectation was associated with activation of the ventral striatum only in patients currently taking the medication (Abler et al. 2009), suggesting that DA receptor activation predisposes the DA reward system to enhance reward-driven behaviour. The striatal activation, which occurred even in the absence of discernable impulsive DM characteristic of PG, was presumably counterbalanced by the intact OFC serotonergic inhibitory pathway, explaining why patients did not develop PG while under treatment (Abler et al. 2009).

Positron emission tomography (PET) study of patients with Parkinson disease treated with DA agonists with and without PG found that only patients with PG showed decreased binding potential in the ventral striatum during both a control and a gambling task, suggesting greater DA release in this region (Steeves et al. 2009). Increased striatal DA receptor occupancy has been shown in cocaine dependent individuals in response to cueinduced craving in proportion to subjectively reported levels of craving (Wong et al. 2006).

Functional neuroimaging studies also substantiate the involvement of the frontal serotonergic pathway in humans with PG (Potenza et al. 2003a, b; Reuter et al. 2005). Consistent with the proposed role of the frontal inhibitory mechanisms in the model, Potenza 
et al. (2003a, b) showed lower frontal cortex perfusion, particularly in the inhibitory VMPFC when PG subjects were shown gambling-related visual cues, suggesting impaired impulse inhibition. Similar patterns of activation have been observed in individuals with substance users with and without PG (Tanabe et al. 2007).

The importance of fronto-striatal loops in DM on the IGT has been demonstrated in PET studies (Thiel et al. 2003). Examining patients with Parkinson's disease where dysfunctional neurotransmission within the fronto-striatal system has been implicated, Thiel et al. (2003) found decreased activation of the OFC and thalamic deactivation during IGT performance. This demonstrates that the fronto-striatal connections proposed to mediate the motivational components of DM appear more dysfunctional than the cognitively focused dorsolateral prefrontal cortex and lateral OFC in Parkinson's disease.

\section{Pharmacological Evidence}

Earlier studies reviewed by Goudriaan et al. (2004) demonstrated that DA dysfunction is related to PG. Consistent with the role of DA in PG are reports of the initiation of PG in Parkinson's patients when prescribed dopaminergic agents (Giladi et al. 2007). Indeed, studies have found that D1 receptors function to shift the focus to the immediate source of gratification or reward whereas D2 receptors enhance this effect by filtering out competing information (Assadi et al. 2009). Paradoxically, Bergh et al. (1997) found decreased DA in problem gamblers' CSF, whereas Shinohara et al. (1999) found increased levels of peripheral DA following gambling activity (specifically a winning streak) in Pachinko players. The disparate results may reflect the non-linear nature of DA's relationship with poor performance on DM as well as the crucial involvement of other pharmacological systems in PG.

Administration of D-amphetamine, which stimulates dopaminergic activity, has been reported to increase the motivation to gamble in a group of problem gamblers (Zack and Poulos 2004). Conversely, administration of haloperidol, a D2-like receptor antagonist, was similarly associated with increased motivation to gamble (Zack and Poulos 2007). According to Topf et al. 2009, this study explains in part, why D2-like antagonists such as olanzapine, have not reduced gambling urges in clinical trials (Fong et al. 2008; McElroy et al. 2008). Studies of individuals with Parkinson's disease provide additional evidence for the role of DA in PG and other disorders of impulse control. In particular, compulsive gambling and sexual behaviors are more common in patients with Parkinson's disease taking dopamine agonists (Weintraub et al. 2006). The reported effects of DA agonists on impulsive behavior have also been reported in patients with fibromyalgia (Holman 2009).

Our proposed psychobiological model posits that 5-HT is deficient in PG, and therefore the inhibitory influence is overridden by the immediate reward focus. Indeed, lower cerebrospinal fluid levels of 5-HIAA, a metabolite of 5-HT have been reported in male problem gamblers (Nordin and Eklundh 1999) whereas enhanced levels of 5-HIAA and decreased tryptophan and 5-HT have been reported in problem gamblers compared to healthy controls (Nordin and Sjodin 2006). Studies have demonstrated that rapid dietary tryptophan depletion alters DM (including those related to gambling) in healthy volunteers (Rogers et al. 1999). Pharmacological challenge studies suggest decreased serotonin synaptic activity in PG (DeCaria et al. 1996). Administration of serotonin receptor agonist, meta-Chlorophenylpiperazine ( $\mathrm{m}-\mathrm{CPP})$, has been reported to generate a behavioral high and increase prolactin levels (a process thought to be mediated by postsynaptic 5-HT1A/ $2 \mathrm{~A} / 2 \mathrm{C}$ receptors) in subjects with $\mathrm{PG}$ relative to controls (Pallanti et al. 2006). Another line of evidence rests on decreased platelet MAOB activity in pathological gamblers as 
compared to healthy volunteers (DeCaria et al. 1996; Blanco et al. 1996; Carrasco et al. 1994; Moreno et al. 1991; Blanco et al. 1996).

The efficacy of SSRIs in the treatment of PG remains inconclusive (Grant and Kim 2006). Effective treatment of PG via the administration of selective serotonin reuptake inhibitors (SSRIs) supports this theory as increasing 5-HT activity in the brain could help mute reactive DA systems in problem gamblers (Hollander et al. 1998; Kim et al. 2002; Pallanti et al. 2002a; Zimmerman et al. 2002). In an 8-week, randomized, double-blind, placebo-controlled trial, Kim et al. (2002) found that the SSRI paroxetine was effective in reducing self-endorsed gambling urges. Conversely, a 16-week randomized placebo-controlled trial of paroxetine found no differences between those receiving the active treatment versus the placebo group (Grant et al. 2003). The efficacy of other SSRIs in reducing gambling tendencies has also been disputed. Sertraline failed to be effective in reducing PG symptoms in a double-blind, flexible-dose, placebo-controlled study (Saiz-Ruiz et al. 2005) whereas in different studies, fluvoxamine has both been successful (Hollander et al. 2000), and unsuccessful in reducing PG symptoms (Blanco et al. 2002). Important information accruing from these studies includes: (a) some SSRIs may be effective in treating some aspects of PG; (b) the dose required for effective treatment seems to be higher than required for depression, akin to that required for treating obsessive-compulsive disorder (OCD); and (c) SSRIs reduce PG symptoms even in patients without comorbid depression or anxiety (Grant and Kim 2006). The lack of a single intervention being effective with all PG sufferers is consistent with a model ascribing potentially similar problem behaviours to a number of causes within a system.

In conducting future clinical trails on the effects of SSRIs in PG, researchers must be cognizant of the different 5-HT receptor subtypes that may be preferentially deficient and the particular PG symptoms that are and are not alleviated with treatment.

The most direct evidence for the relationship between dopamine and serotonin during DM comes from animal studies. Winstanley et al. (2006) used in vivo microdialysis in rats performing the delay-discounting task to demonstrate increased 5-HT levels in the medial PFC but not the OFC during task performance, and increased 3,4-di-hydroxyphenylocetic acid (DOPAC; a metabolite of dopamine) levels in the OFC only in the animals performing the task, but not control animals (Winstanley et al. 2006). This study suggests not only a distinction in cortical involvement in gambling tasks, but also consistent with the proposed model, points to a clear dopamine-serotonin double dissociation.

Further Decisional Antagonism: Roles of Testosterone (T) and Cortisol (C)

van Honk and his colleagues have empirically demonstrated that the anabolic male hormone, $\mathrm{T}$ has a facilitating effect of immediate reward focus while the stress hormone, $\mathrm{C}$ has an inhibitory effect during the IGT. van Hank et al. (2003) experimentally demonstrated that high $\mathrm{C}$ levels were associated with a bias toward punishment sensitivity and negatively associated with reward focus. This negative reciprocal relationship between the effect of $\mathrm{T}$ and $\mathrm{C}$ is intuitively appealing as well. High $\mathrm{T}$ levels are associated with social dominance (Dabbs and Dabbs 2000) that encompasses a tendency to approach goals and "go for it now." Alternately, cortisol stress-inducing mechanisms tend to increase wariness of new stimuli because one's antennae are tuned to the possibility of negative outcomes (van Hank et al. 2003). Consistent with this, administration of $\mathrm{T}$ to healthy females produced a more disadvantageous pattern of decision-making response in the IGT task, consistent with reductions in punishment sensitivity and/or heightened reward dependency (van Honk et al. 2004) as proposed by the model. Also supporting the role of C in PG, transient 
increases in cortisol have been noted in gambling studies of volunteers recruited from casinos (Roy et al. 1988). Stressful life events involving early life trauma have been implicated in PG as well as drug addiction in humans (Scherrer et al. 2007) and increased levels of alcohol consumption in monkeys subjected to stressful maternal separation (Fahlke et al. 2000) .

Potentially contrary evidence was reported by Ghebrial (2006) in a study of psychopathic men and women. In male psychopaths, high post-gambling $\mathrm{T}$ levels were associated with better IGT performance whereas in females, lower post-task T levels and low basal C levels were associated with better IGT performance. Similarly, Blanco et al. (2001) did not find differences in resting $\mathrm{T}$ levels between $\mathrm{PG}$ and non-PG groups.

A study by Meyer et al. (2000) offers one possible explanation for these discrepant findings. Their study examined $\mathrm{C}$ levels in individuals who gambled at least once per week while they participated in a game of blackjack. They found that $\mathrm{C}$ levels were higher in participants who played with their own money compared to those who wagered points. Therefore, it is possible for gambling simulation experiments to provide discrepant results depending on their ability to simulate the motivational conditions present in "real-world" gambling. In addition, the findings presented by Ghebrial (2006) likely do not apply to most problem gamblers. Psychopaths are likely atypical in a number of ways and while risk of PG may be elevated in psychopaths, firm conclusions cannot be drawn to non-psychopathic problem gamblers. Further, the proposed model is more concerned with dynamic shifts in $\mathrm{T}$ activation in response to opportunities for immediate reinforcement rather than absolute values. Consistent with this idea, Terburg et al. (2009) have recently presented a complex and compelling argument for the T/C ratio biasing approach-avoidance decisions in social aggression. This suggests that our model may extend beyond PG and represent a central mechanism for DM for motivational decisions in general.

Finally, we propose that the $\mathrm{T}$ and $\mathrm{C}$ systems do not work in isolation of each other but rather that DA and $\mathrm{T}$ act synergistically to stimulate approach to targets of gratification while 5-HT and C work synergistically to inhibit rapid approach to potentially rewarding stimuli, and shifting of motivational focus to potentially long-term negative outcomes.

\section{A Role for Nor-Epinephrine in DM Related to Problem Gambling}

Kerfoot et al. (2008) suggest a role for NE in enhancing memory under stressful conditions that reflects monitoring of peripheral hormonal and autonomic function via a NE-dependent Nucleus Tractus Solitarius (NTS)-Accumbens shell mechanism. Alexander et al. (2007) subjected participants to the Trier social stress manipulation utilizing both cognitive flexibility and more routinized tasks (public speaking and mental arithmetic vs. a nonstress reading and counting task). They found that stress conditions produced performance deficits relative to the non-stress conditions, but only in the more complex flexibility tasks but not in the concrete reading and counting tasks. However, the deleterious effects of stress on cognition were entirely reversed for the experimental group taking propranolol, a non-specific beta-adrenergic (NE) receptor blocker. This strongly suggests that the negative effects of stress on higher cognition are mediated at least in part through the NE receptor system. NE elevations might similarly be involved in the arousal phase or when the problem gambler experiences stress-inducing meaningful losses. This may also feed into or from the $\mathrm{C}$ stress system as it is well documented (e.g., Thompson and Thompson 2003, pp. 106-107) that stress-induced NE elevation gives way after about 20 min to rises in $\mathrm{C}$ levels, associated with a more prolonged stress experience. 
Propranolol reportedly produces a selective change in DM, suggesting that NE modulates the processing of punishment signals when choosing between probabilistic rewards and punishments under conditions of increased arousal (Rogers et al. 2004). Two other studies supported these findings in Australian and Japanese subjects (Shinohara et al. 1999; Meyer et al. 2004). In addition, an elevated growth hormone response to the alpha adrenergic receptor agonist Clonidine was found in male pathological gamblers compared to healthy controls (Comings et al. 1996). The involvement of NE in PG is further supported by studies showing significantly higher blood NE levels across the entire gambling session (Blaszczynski et al. 1986) and higher urinary noradrenergic output and higher CSF NE (Roy et al. 1988) in problem gamblers as compared with controls. Further, Comings et al. (2001) reported an association between the $\alpha$-2C adrenergic receptor gene $(\alpha 2 \mathrm{cAR})$ and PG.

Other studies confirm that problem gamblers demonstrated noradrenergic dysfunction (DeCaria et al. 1997; Schmitt et al. 1998; Shinohara et al. 1999) and have shown higher levels of peripheral NE and blood epinephrine either during gambling or on days of high levels of gambling activity (Goudriaan et al. 2004). Schmitt et al. (1998) also demonstrated this in an aboriginal population in Australia. A study in Japan using the Japanese game Pachinko for regular players, NE levels were significantly greater when in the Pachinko (gambling) center, when a winning streak started, when it ended and 30 min later, in comparison to a laboratory setting (Shinohara et al. 1999). This also shows the importance of environmental cues as activating putative neurobiological systems that in turn influence DM.

These findings suggest a possible role for NE in mediating poor DM in problem gamblers. However, these studies did not examine changes in levels of NE from basal to post-gambling states. In line with previous literature, the present model contends that very high levels of NE, possibly by narrowing the focus of attention, contribute to poor DM, but only in individuals who experience high levels of stress which impairs the ability to approach the DM process rationally. However, with individuals experiencing moderate basal levels of $\mathrm{NE}$ and a modest rise in $\mathrm{NE}$, a subsequent delayed rise in $\mathrm{C}$ would result, favoring a cautious, long-term approach. Thus the present model contends that it is the reactivity of the NE system, and not merely basal levels of NE, that determines DM.

\section{Role for Gamma-Amino Butyric Acid (GABA) in PG}

GABA receptors are the primary targets of a number of sedative/anxiolytic drugs. There is increasing support for effects of modulation of GABAergic systems on substance use disorders (Kaufman et al. 2002). Brebner et al. (2002) found that GABAB agonists such as baclofen effectively reduce cocaine self-administration most likely via inhibition of dopamine reward circuits. Studies have shown that GABA agonists applied to the cingulate motor area impaired the ability of monkeys to switch responses when they encountered reduced rewards (Shima and Tanji 1998). GABA may also curb impulsive approach for gratification by inhibition of opioids (Brebner et al. 2002). While these studies suggest a role for GABA in mediating DM and monitoring performance, the direct involvement of GABA in PG has yet to be established.

\section{A Role for Glutamate in PG}

Current thinking and empirical evidence is now assigning a central role to Glutamate (Glu; also known as glutamic acid) in regulating the DA-reward experience. Glu is a natural 
amino acid and protein component that also functions as the most widespread excitatory neurotransmitter in the brain (Stahl 2008). Atypically, in its neurotransmitter role, it is synthesized in glial cells (not neurons) from glutamine. Glu is released from neuronal vesicles to affect neurotransmission, but is then taken up by local glial cells by an excitatory amino acid transporter (EAAT). In the glial cell, Glu is converted to glutamine enzymatically by glutamine synthetase. Glutamine in turn is shunted out of the by a reverse transporter/pump called specific neutral amino acid transporter (glial SNAT). Once in the cytoplasm, glutamine can enter neurons via reversed SNATs. Inside the neuron, glutamine is enzymatically converted in mitochondria by glutaminase to Glu. Neuronal Glu is then transported into protective vesicles by a vesicular glutamate transporter (vGluT) and stored until required for neurotransmission (Stahl 2008). Thus Glu is constantly being recycled and regenerated and shunted between neuronal, extracellular and glial compartments.

Three groups (and 8 sub-types) of metabotropic receptors exist for Glu along with 3 post-synaptic ionotropic receptor classes: AMPA, Kainate and NMDA. The Metabotropic receptors can function as (presynaptic) autoreceptors to inhibit Glu release. The NMDA receptor requires one of two co-transmitters, principally glycine but also d-serine. The NMDA receptor has been most closely associated with long term potentiation representing a cellular model for learning (Stahl 2008).

It has been shown that Glu modulates DA activity in the VTA-NAcc pathway (e.g., Krystal et al. 2003), presenting a clear pathway for Glu to impact the reward focused effect of DA on DM. Consistent with Glu's role in learning (i.e., long-term potentiation) this role for Glu involves linking new stimuli (drugs) and behavioral responses with an unconditioned (pleasurable) response. In their addictions model, Kalivas and Volkow (2005) noted contiguity of Glu with DA many of the reward experiencing and regulating circuits including the VTA, NAcc, basolateral amygdala and likely regulatory prefrontal cortex. The immediate relevance of Glu for $P G$ was shown in a pioneering intervention study by Grant et al. (2007). They successfully treated 16 of 27 individuals meeting DSM-IV criteria for PG using the amino acid, $\mathrm{N}$-Acetyl-Cysteine (N-A-C), a cysteine pro-drug. $\mathrm{N}-\mathrm{A}-\mathrm{C}$ reduces the synaptic release of glutamate by increasing the extracellular fraction of Glu and stimulating inhibitory metabotropic glutamate receptors. Cravings and accompanying compulsive behaviors are reduced when extracellular Glu concentrations are restored in the NAcc. Contextualizing the shift between substance abuse and addiction, Ross and Peselow (2009) provide an executive dysfunction model for addictions in which dysregulated Glu transmission originating in the orbital PFC terminates in the NAcc to focus on drug as opposed to more natural and meaningful reinforcing stimuli. Kalivas (2009) presented a highly detailed summary of current knowledge on the role of Glu in addictions. Dubbed the "Glu homeostatic theory of addictions", the approach is based upon consistent findings that Glu functions not only as a classic synaptic neurotransmitter, but also is absorbed by glial cells to terminate synaptic activity and serve as storage depot awaiting future use. Functionally, (a) extracellular Glu is produced in glia, (b) metabotropic Glu receptors (mGluR's) are controlled by non-synaptic Glu, and (c) ionotropic Glu Receptors (iGluR's) in the synaptic cleft are protected from exposure to non-synaptically released glutamate and (d) Glu uptake reduces the effects of synaptic Glu release on mGlu receptors in synaptic regions (Kalivas 2009). Because the majority of Glu in the NAcc is provided by Glu-cysteine exchange, processes and drugs (such as $\mathrm{N}-\mathrm{A}-\mathrm{C}$ ) that inhibit that exchange will reduce the availability of Glu in the "rewardexperiencing" NAcc. Additional details of this mechanism are provided in Kalivas (2009).

The salience of this mechanism is that a balance between synaptic and glial Glu is necessary for effective PFC control over the reward-sensitive NAcc. Too little glial Glu results in excessive synaptic Glu release that, in turn, strongly enhances NAcc DA release 
and a bias toward DM favoring immediate gratification. It should also be noted that Glu has a negative reciprocal relationship with the inhibitory effects of GABA. Consequently, GABA can affect DA release both directly and through the synaptic NAcc intermediary. Psychologically, Stahl (2008, p. 948) states, "this reactive reward system pathologically 'learns' to trigger drug seeking behavior and 'remember' how to do this when confronted with internal cues such as craving and withdrawal and external cues from the environment such as people, places and paraphernalia associated with past drug use”. Consequently, we propose that Glu is a necessary element for understanding the psychopharmacological basis of DM in PG. Psychologically, Glu at the NMDA receptor would seem to facilitate memory formation linking specific stimuli and behavioural responses to the DA and endorphin mediated rush associated with PG.

\section{Putative Role for Endorphins in PG}

Gambling or using substances for pleasurable consequences triggers the release of dopamine, an effect that is intensified by endogenous opioid release (Grant and Kim 2006). Indeed, gambling has been associated with elevated bloods levels of endogenous opioids (Grant and Kim 2006). Similarly, individual differences in the sensitivity of the opioid system have been linked to alcohol addiction (Gianoulakis 1996).

Pharmacological manipulation of the opioid system can modulate the pleasurable effects of gambling behavior. Opioid agonists intensify DA release in the nucleus accumbens, thereby greatly enhancing pleasurable sensations, leading to the orgasm-like rush. Opioid receptor antagonists, in reverse, inhibit DA release in the nucleus accumbens and ventral pallidum through the disinhibition of GABA input to the DA neurons in the VTA (Ronken et al. 1993), thus dampening gambling-related excitement and cravings.

Two opioid antagonists, naltrexone and nalmefene have been shown to be effective in the treatment of PG in placebo-controlled, double-blind, randomized trials (Grant et al. 2006; Kim et al. 2001). Studies have demonstrated the ability of naltrexone to decrease the strength and frequency of pathological gamblers' urges to gamble, their thoughts of gambling, and their actual gambling activity (Kim and Grant 2001; Kim et al. 2001; Pirastu et al. 2006). However, the effects of naltrexone have proven more robust in the treatment of people who described their urges as severe than in those who described their urges as more moderate (Kim et al. 2001).

Nalfamene, another opioid antagonist has also been reported to significantly improve gambling symptoms relative to a placebo (Grant and Kim 2006). Similarly, buprenorphine, a mu-receptor antagonist, improved performance on the IGT in opiate-dependent subjects relative to methadone maintained individuals (Sofuoglu et al. 2006). These findings are consistent with the role of the endogenous opioids in intensifying the hedonic effects of DA in problem gamblers. Specifically, opioid antagonists act to control the release of DA within the mesolimbic pathway. By reducing the supplemental release of DA, opioid antagonists assist in relieving the intense focus of pathological gamblers on immediate reward, affording their other inhibitory influences to be more effective in the DM process (Grant and Kim 2006).

\section{A Review of Pharmacological Intervention in Problem Gambling}

The described model implicitly suggests that pharmacological interventions targeting the identified transmitter/neuromodulator systems should be effective in reducing pathological 
and problem gambling behavior. We examine this suggestion empirically, by reporting and interpreting Effect Sizes (ES) associating pharmacological treatments for PG and outcomes.

Methods

\section{Search Criteria}

General guidelines for inclusion of papers in systematic PG reviews have been furnished recently by Johansson et al. (2009) They identified stringent design quality and documentation criteria. These include (1) original research on PG, (2) study is published in international journal (i.e., exclusion of "gray literature" etc.), (3) sample size is specified, (4) the instrument used to identify PG is specified, (5) the design is specified, (6) adequate statistical analyses were conducted, (7) documentation was adequate and (8) results were conclusive.

Electronic databases (Scholar's Portal and PubMed) were searched for clinical trials published between 1985 and 2010 using the following index terms: gambl* AND treat* or therap*. The reference lists of articles that were retrieved were visually searched for additional relevant publications. Initially, we intended to limit included papers to: randomized controlled trials published in a peer-reviewed journal; inclusion of adults (18 years or over) who were classified as pathological gamblers by an interview or a questionnaire at the start of the study; inclusion of an adequate control group (waitlist or receiving either a placebo or behavioral intervention); inclusion of a treatment group receiving a pharmacological agent; outcome measure included at least one indicant of gambling urges and/or behavior. Due to the paucity in published research on this topic, all clinical trials (double-blinded, single-blinded or open-label) were included. Studies were excluded if they: included problem gamblers with concurrent psychiatric, neurological or substance abuse disorders; were case reports; and were not published in English.

\section{Design Strength Characteristics}

Studies in general vary in terms of design strength leading researchers to more highly value information accruing from stronger studies and discounting to varying degrees studies with weaker designs (Hanson et al. 2009). Although some design features such as randomized assignment are universally regarded as optimal, Hanson et al. (2009) note that reviewers often disagree about which papers within a literature exemplify stronger or weaker designs. Additionally, design strengths of particular domains are nuanced by theoretical and practical features. For example, Hanson et al. (2009) describe seven categories for judging the relative design strength for sex offender treatment studies. These include (1) administrative control of independent variables, (2) experimenter expectancy, (3) sample size (strong studies $>100$ ), (4) attrition (strong studies $<20 \%$ ), (5) group equivalency prior to treatment, (6) outcome variable validity, and, (7) appropriateness of comparisons conducted. They also note that follow-up periods should cover 2 years and 10 year periods are preferable.

Although sexual offending and PG may share some characteristics (e.g., "impulsivity" in some cases), intervention programs are implemented differently. For example, no identified PG intervention studies followed patients for more than 25 weeks (6 months); an understandable practice since unlike forensic psychologists and criminologists, PG researchers do not have the criminal justice system and its computerized record keeping 
system to provide relapse data for a decade or more. Our Design Strength analysis focused on PG issues and realities reflected in the extant literature.

\section{Effect Size Calculation}

All ES calculations were done using two meta-analysis programs, ClinTools (Devilly 2005) and D-STAT. ES was calculated from raw data whenever possible (i.e., M2-M1/ S.D.). In keeping with recent trends (Capraro 2004; Kline 2005; Wilkinson and [APA] Task Force on Statistical Inference 1999), we provide the 95\% confidence intervals (C.I.) for each calculated ES. If the C.I. of an ES include the value of 0 (i.e., lower limit $=$ or $<0$ ), one cannot rule out sampling variability as the reason for observing the effect magnitude with $95 \%$ confidence. A relatively substantial ES coupled with a non-significant C.I. typically reflects a relatively small sample size.

For studies with a total of 40 participants or less, the more conservative Hedges Correction for Cohen's d was used to reflect the "small n". For larger studies, the uncorrected Cohen's d was calculated. For effects presented in terms of proportions of responders and non-responders in treatment and control conditions, the w statistic was used. For pre-post treatment comparisons absent a control group, the pre-post mean differences were used, although this can result in high ES values (Durlak 1995). None of the reviewed papers contained a "pre-post score correlation coefficient" that can be used to minimize this potentially exaggerated ES (Devilly 2005).

Results

\section{Study Design}

A summary of the design features of pharmacotherapy studies in PG is presented in Table 1 . The columns reflect design issues generally reflecting those identified by Hanson et al. (2009). Column 1 identified the study. Next, to mirror model components, we identified the medication and its primary pharmacological target (Primary Target System; Column 2). The instrument employed for PG status was entered in Column 3 (Gambling Status Measure). The fashion in which individuals were assigned to treatment or control groups appears in Column 4 (Group Assignment). The Pre-Intervention Equivalence of the groups (and whether it was evaluated) is noted in Column 5. The total and group numbers of participants in provided in Column 6. Gambling Type (i.e., slots, horse racing etc.) is listed (when documented) in Column 7. The extent to which participants and experimenters were "blind" to treatment is listed in Column 8 (Bias/Expectancy). The existence and nature of comparison groups (alternative treatment, untreated control etc.) was entered in Column 9 (Comparison Group). The existence of a co-therapy (e.g., Cognitive Behavioral Therapy or CBT) that could dilute the ES of the medication outcome is listed in Column 10. The study's Outcome Measure/s (e.g., Number of Gambling Episodes/Month; YalesBrown Obsessive Compulsive Scale or Y-BOCS; Gambling Severity Assessment Scale or GSAS) is described in Column 11. Duration of follow-up is provided in Column 12. The primary outcome measure(s) are presented in Column 13. Strong study features are designated in the Table itself by upper case, bold, italicized font features. Adequate study features are depicted in bold, italicized but lower case font. Weak study features are displayed in regular lower case font (See legend to Table 1). Descriptions for designation as strong, adequate and weak design features are displayed in the legend as well. 


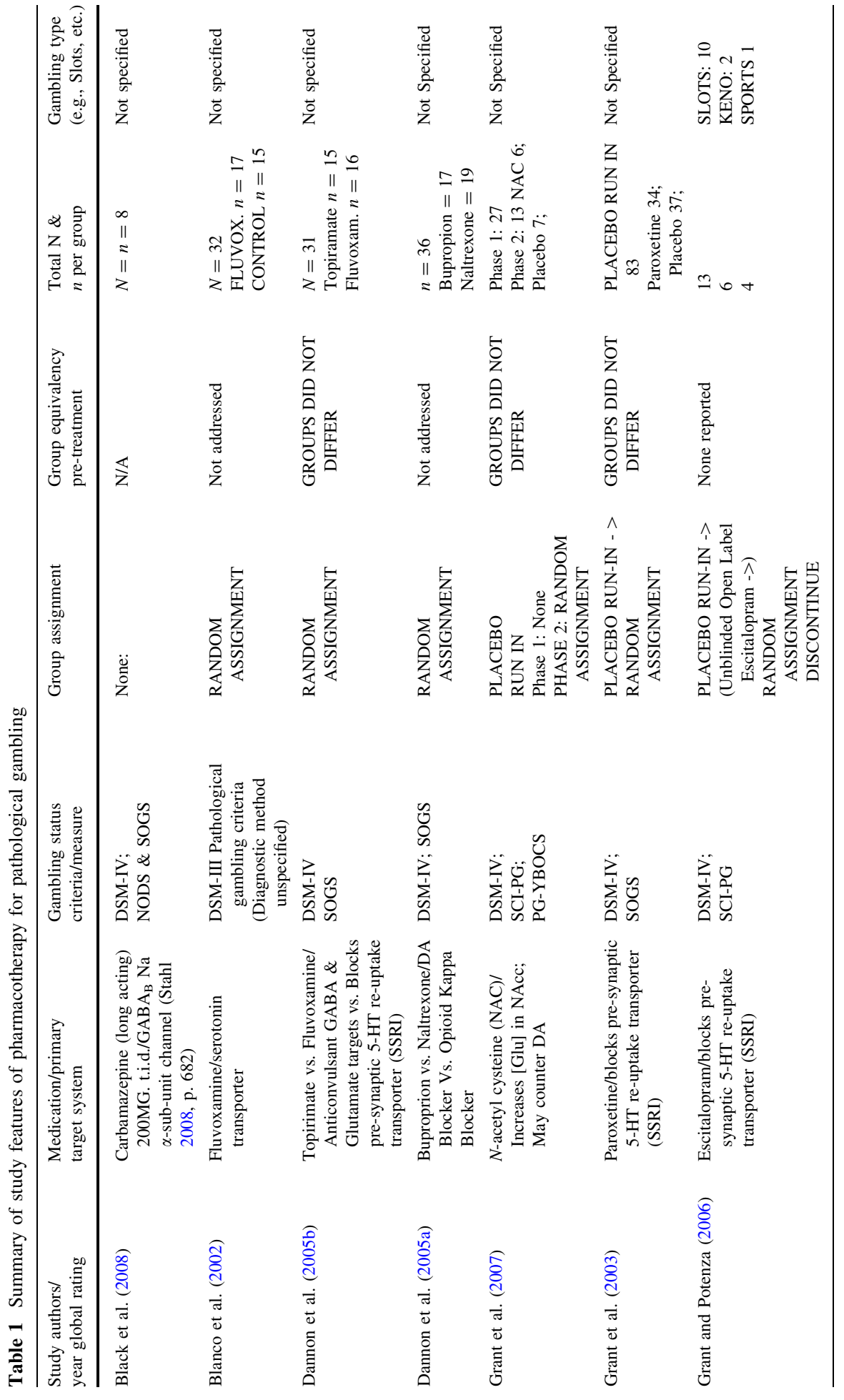




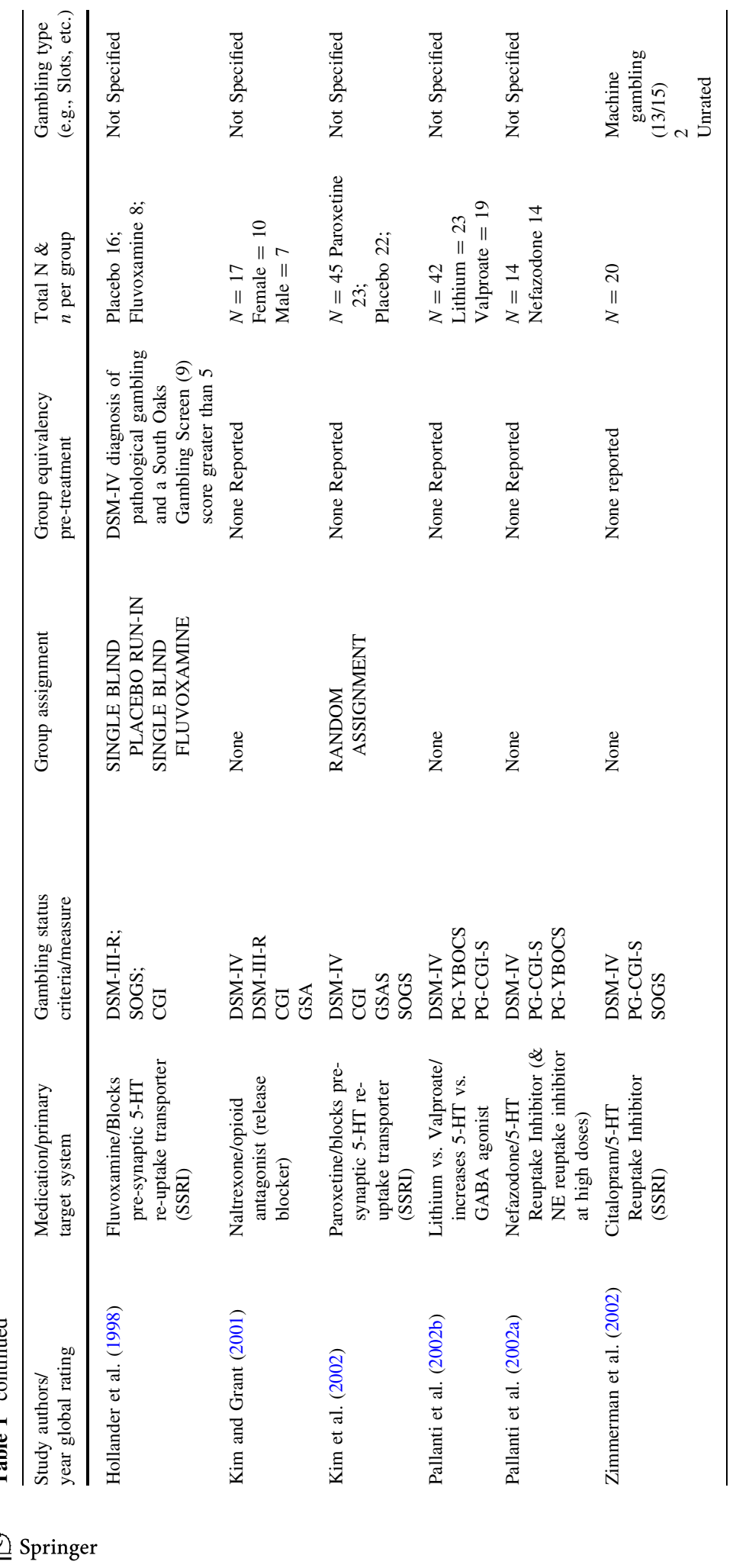




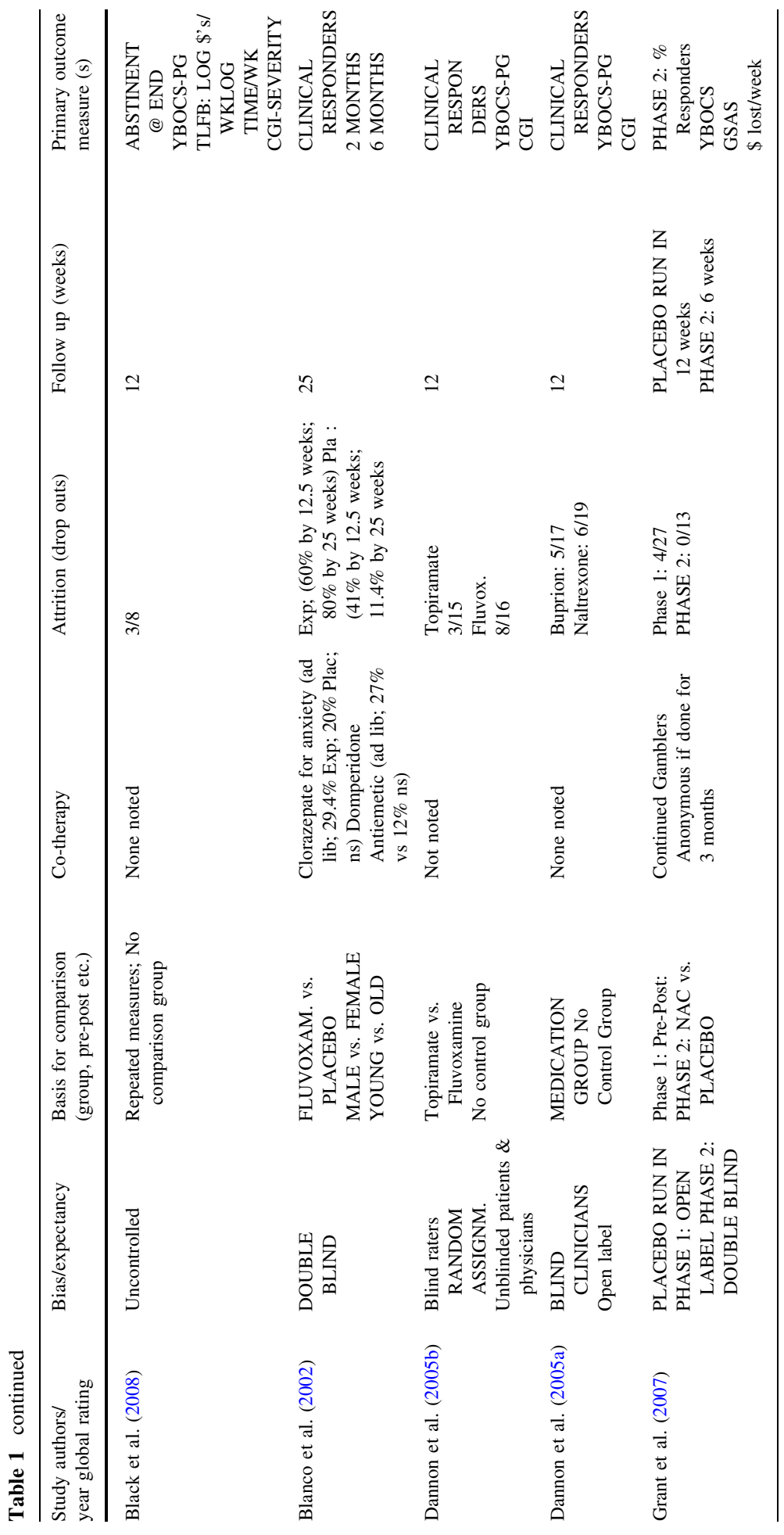




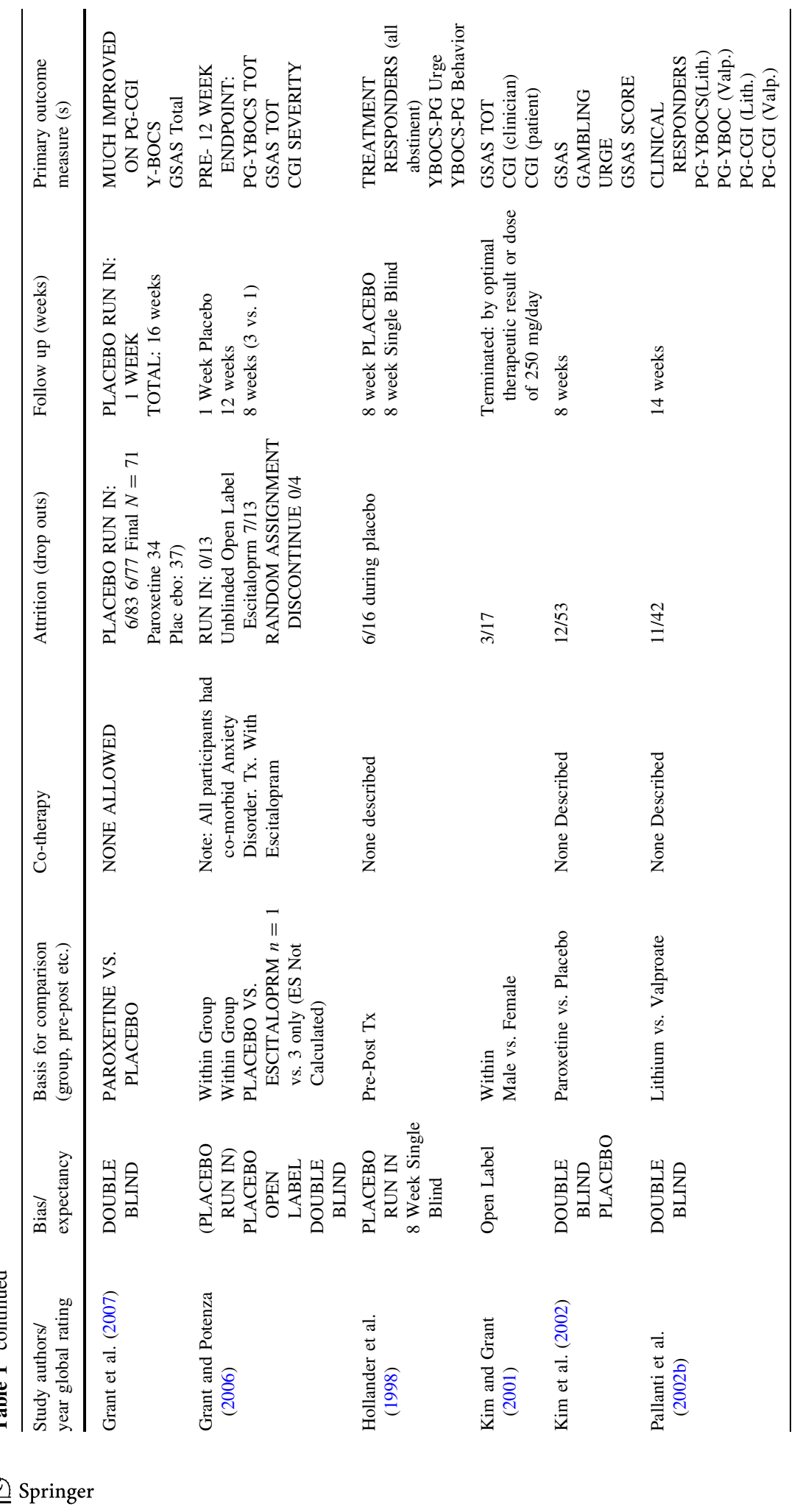




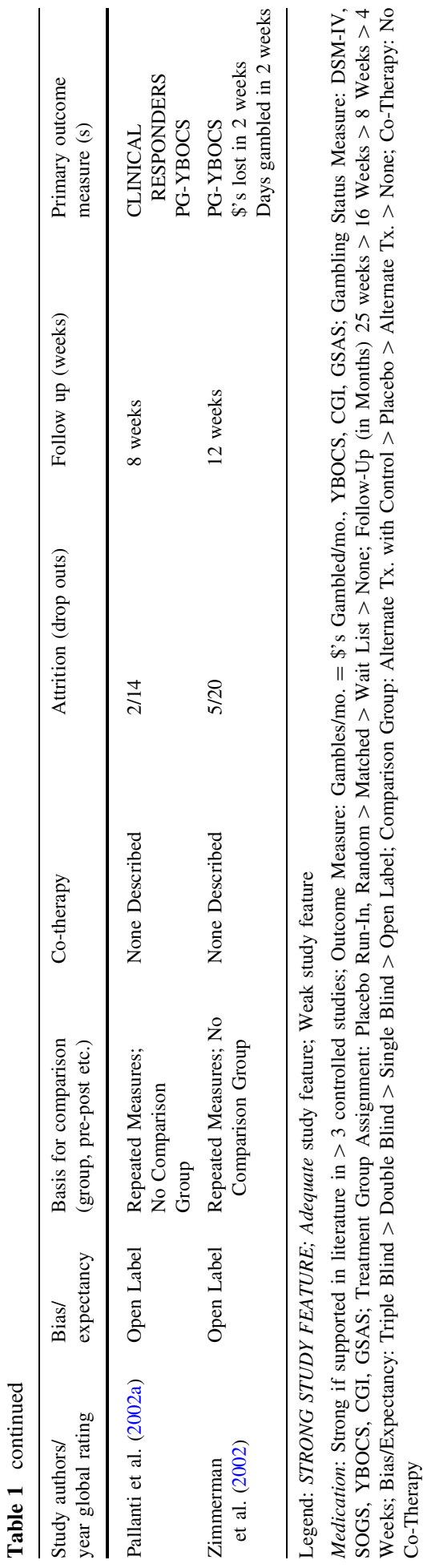


As there is no objective way to quantify and then integrate different design strong and weak points (Hanson et al. 2009), this table is intended to permit the reader a general sense of strengths and weaknesses associated with each paper rather than a ranking or scoring of each paper. Nevertheless, each of the studies included in Table 1 was rated for design strength or weakness by two of the authors (SB \& SB) who agreed on 12 of the 13 studies resulting in an Intraclass Correlation Coefficient of $0.914(p=0.0001)$. Despite the array of medications, neurobiological targets, and various design features populating the table informed raters can reliably designate studies as strong or weak. One relatively novel design merits some comment. Observations that PG symptoms remit relatively quickly in a substantial number of the Placebo group members leads to the concern that the effect of a medication could be underestimated in light of the comparison between the experimental and positively affected placebo group members. To eliminate this threat to internal validity, a number of the papers (e.g., Grant et al. 2003; Grant and Potenza 2006; Hollander et al. 1998) used a "Placebo Run-In" design in which all participants are initially placed on placebo. Those who respond positively within the initial weeks or two are withdrawn from ongoing pharmacological treatment, thereby minimizing, if not eliminating, individuals prone to placebo effects or spontaneous remissions. The non-responders are then randomly assigned into treatment and placebo groups. This design permits a stronger test of the medication effects per se as "pseudo-responders" in both the experimental and comparison conditions are removed from the study.

Overall, the existing literature shows uniform strength in defining PG (DSM-IV, SOGS) and well-validated pre-port measures to reflect changes in core aspects of PG (i.e., Gambling frequency and losses, YBOCS, GSAS, GCI). Additionally, a number of studies employed the Placebo Run In design to minimize spurious responding. Studies generally precluded potentially confounding concurrent treatments. Follow-up times and attrition rates were understandably limited by clinical realities. About half of the studies did not formally test for effectiveness of randomization. Few studies reported the participants' preferred type of gambling activity. A minority of studies compared only a novel treatment to one that had shown success in the past. While this may be entirely legitimate in its own right, studies where both treatments are of approximately equal efficacy produce a negligible ES. Additionally, given the number of studies available and their diversity, it may somewhat premature to assume that a given pharmacological treatment for PG is firmly established with a stable effect size across different samples. Only three studies (Grant et al. 2003; Kim et al. 2002; Pallanti et al. 2002b) had an initial participant pool of more than 40. In light of the reported attrition rates, one desirable feature for future studies would be an increased number of participants although we are aware that this is subject to the realities of clinical research (i.e., funding, access to appropriate samples etc.).

\section{Effect Size Results}

The ES results are presented in Table 2. It is clear that regardless of medication/target complex, outcome variable (i.e., gambling losses, gambling frequency or psychometric self or clinician rating scales), the reported pharmacological treatments produce relatively robust effects extending to the very strong range. This optimism has to be somewhat tempered by the C.I. analyses show 15 of 24 calculated effect sizes 0 within their $95 \%$ confidence intervals. Statistically then, one cannot conclude within statistical limits that the observed ES values are not due to sampling variability. In light of the robustness of the ES values themselves, this is likely attributable to the relatively small sample size in many of the studies. Larger samples will then better demonstrate the impressive utility of the 


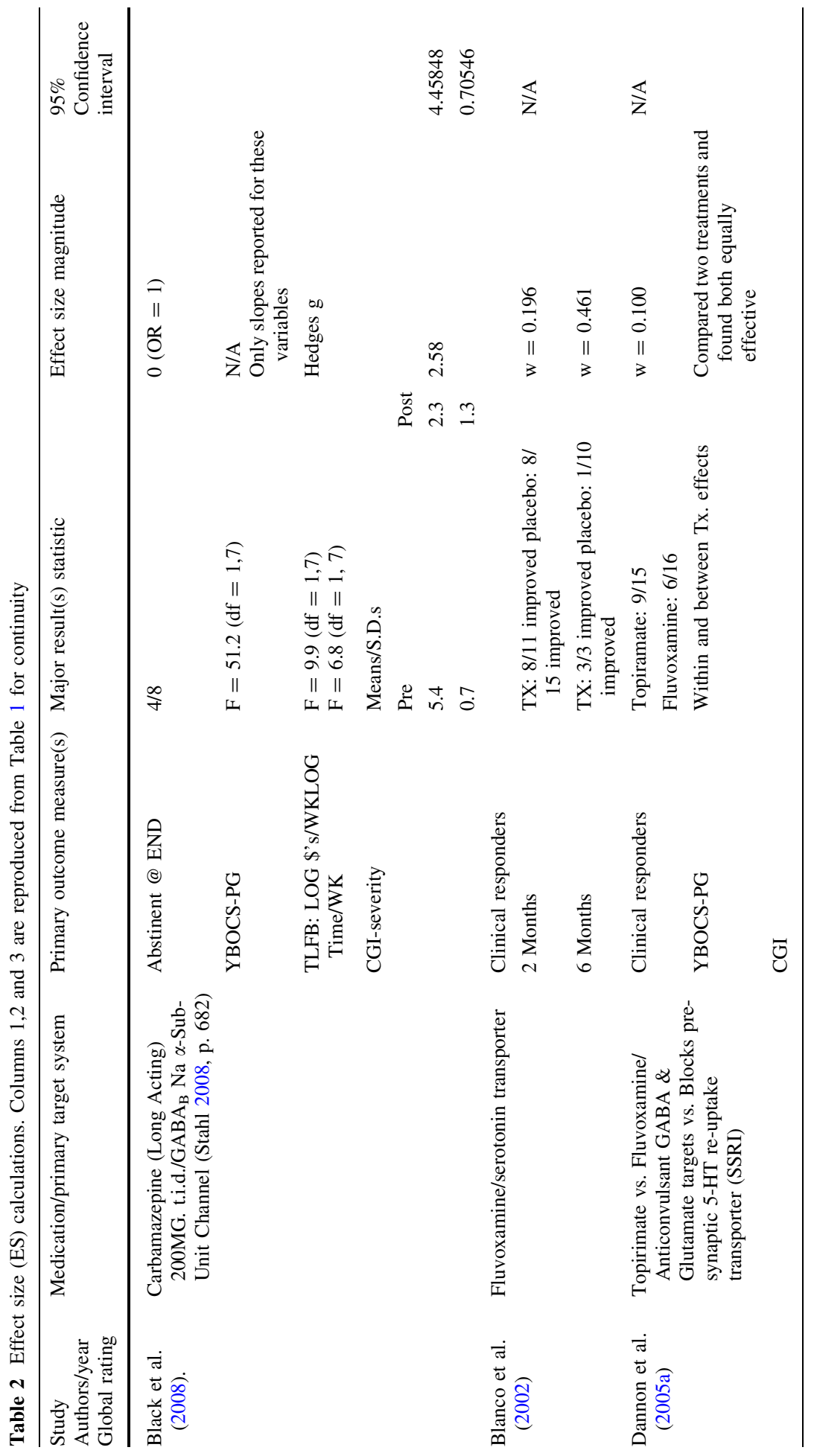




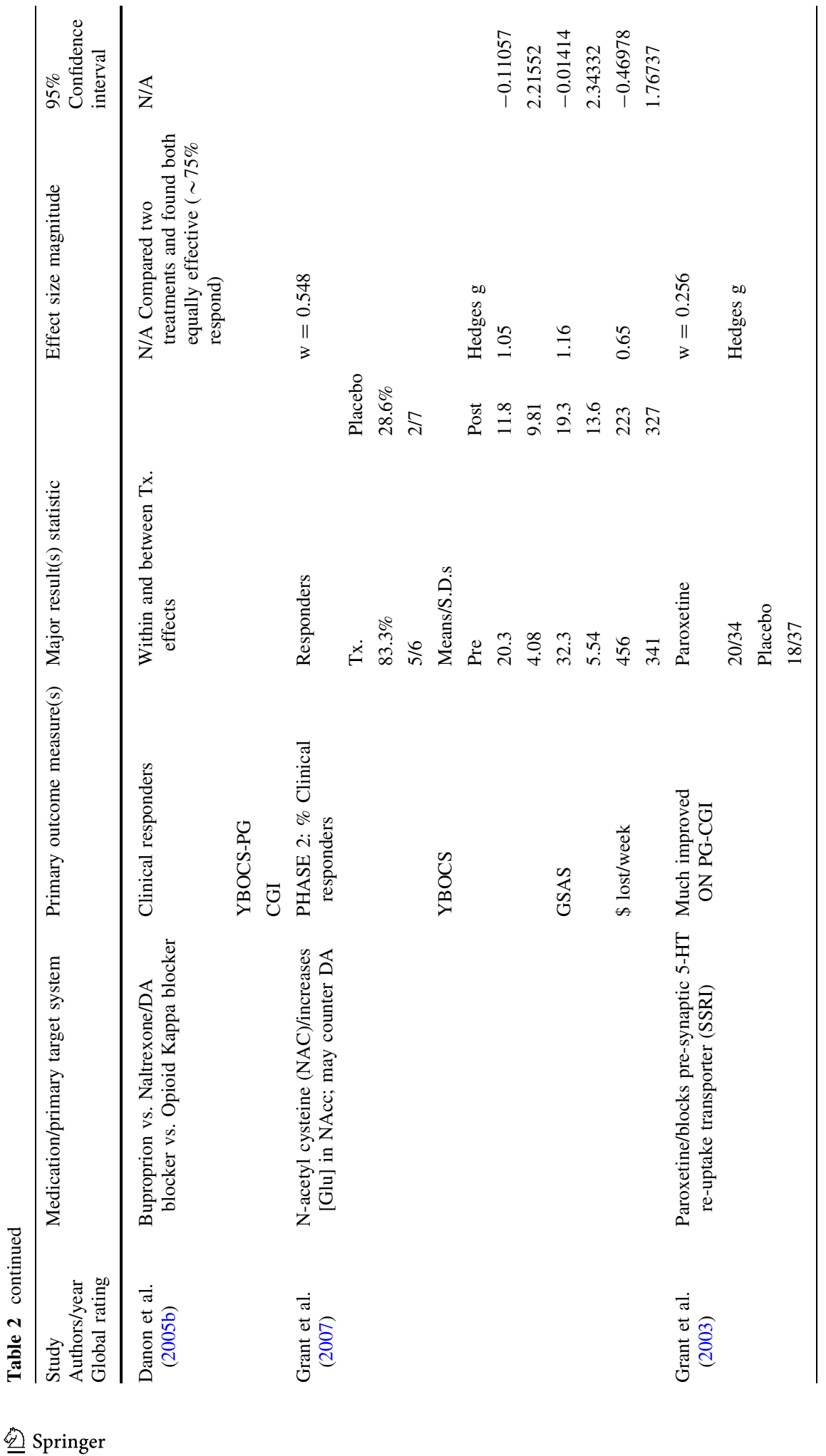




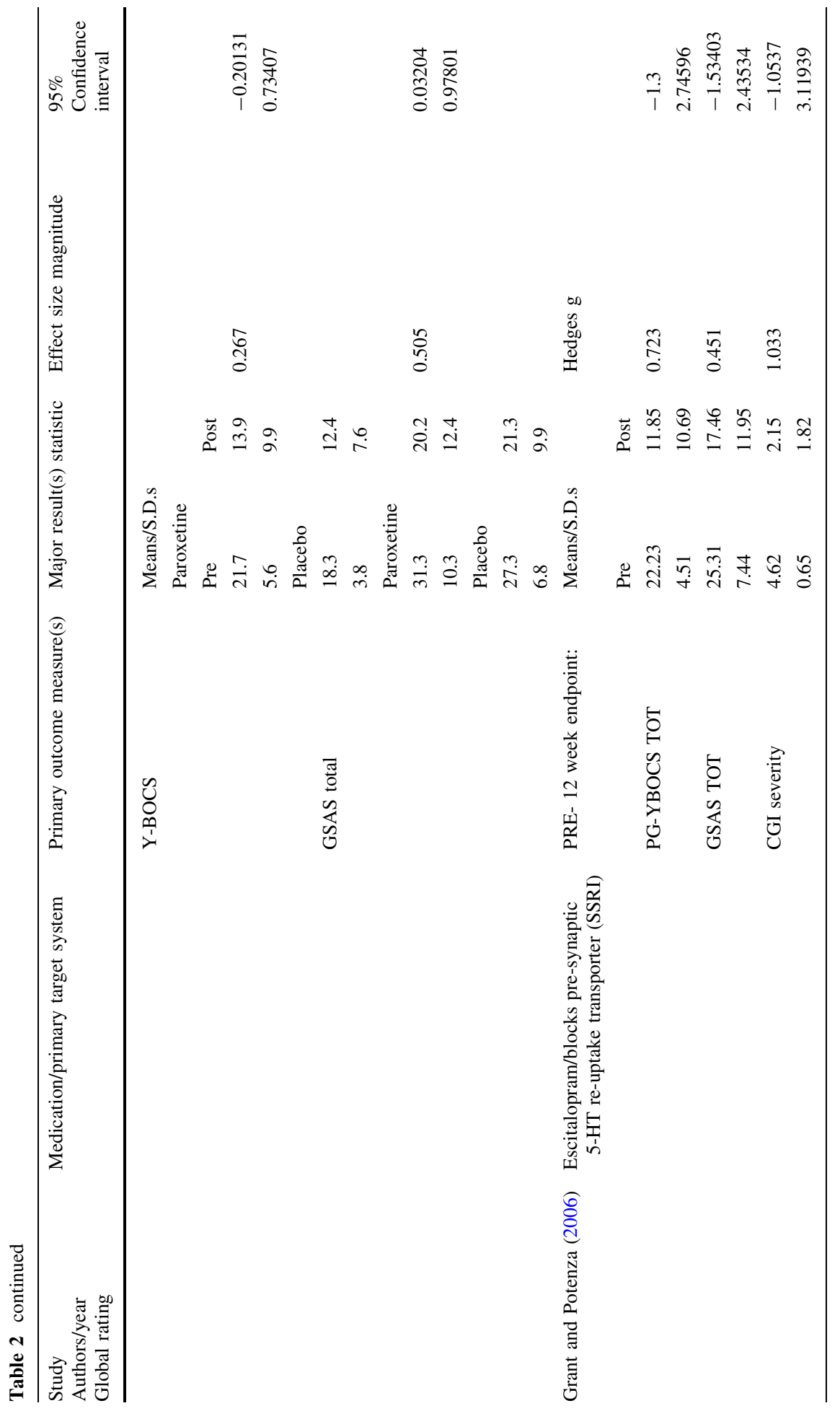




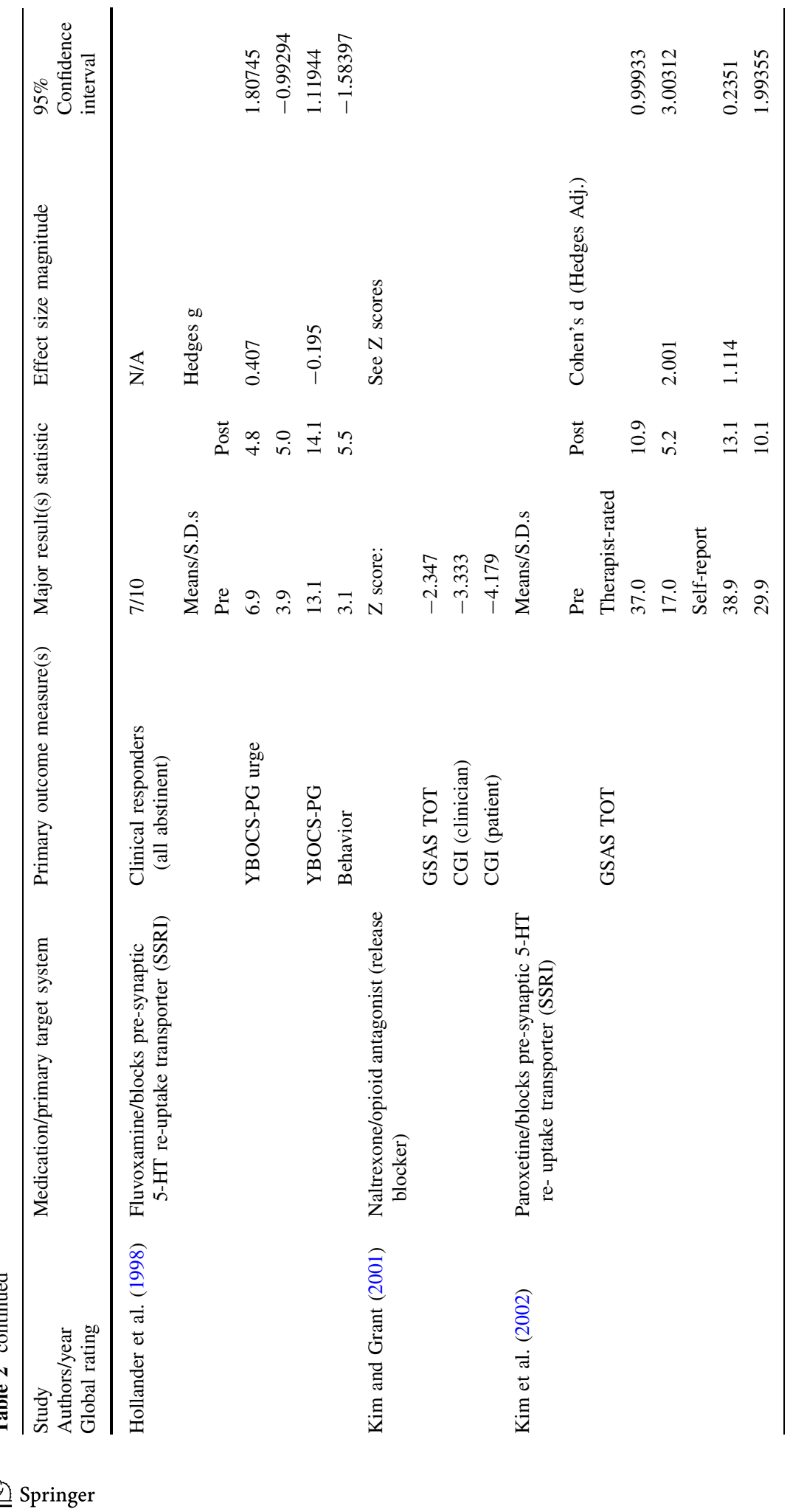




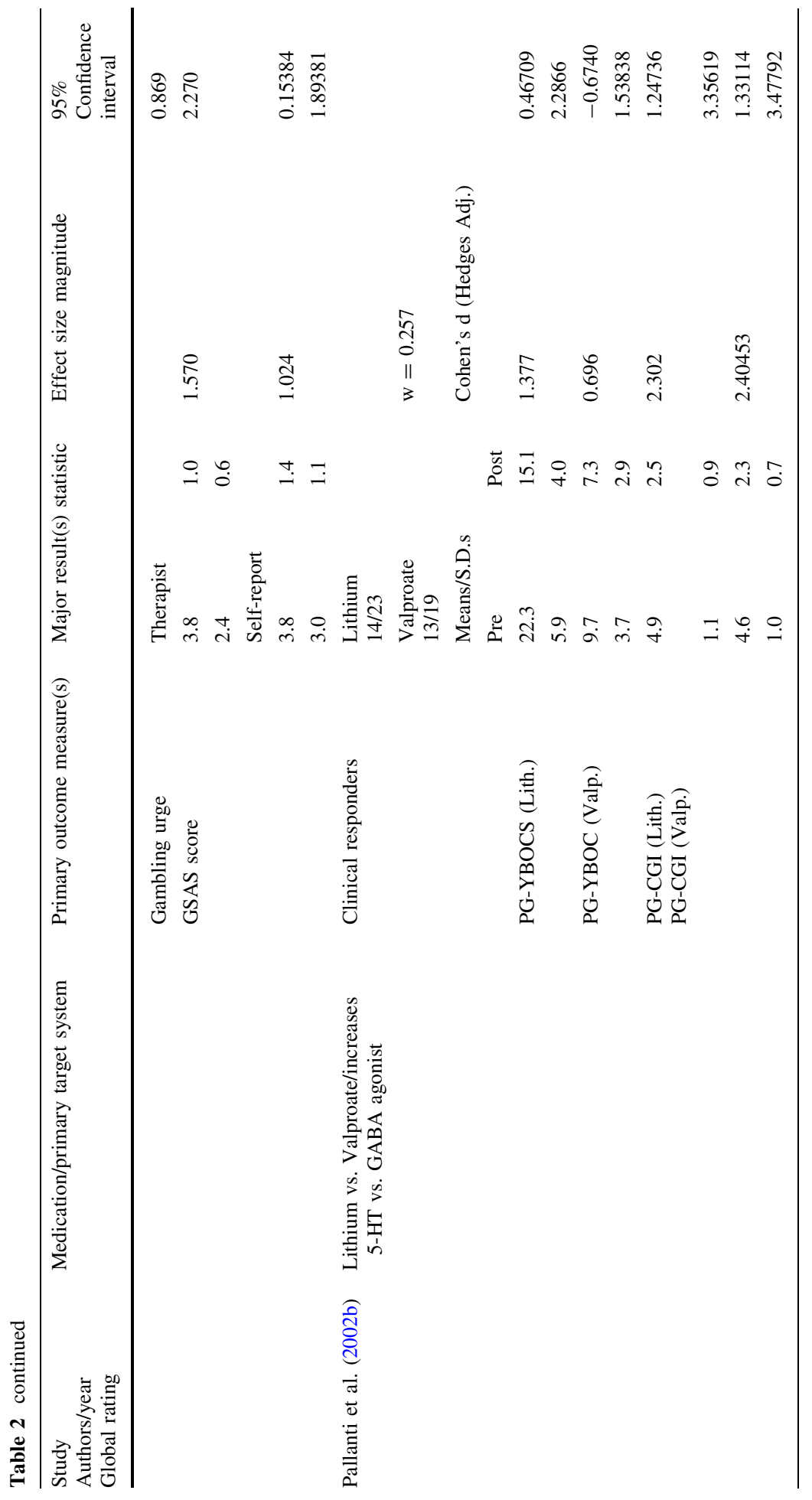




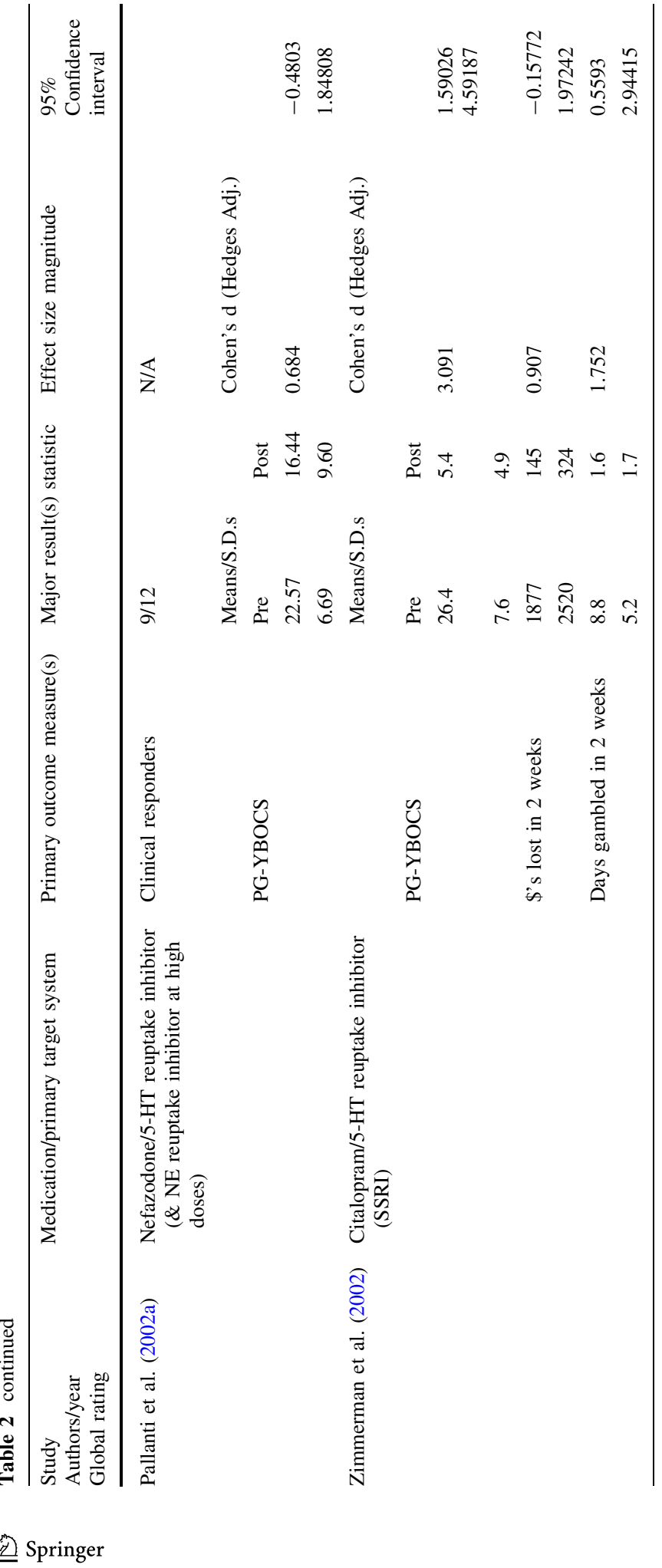


medications. All ES and C.I. calculations were identical to 3 decimal places with the two software packages.

\section{Discussion}

Of paramount importance from our perspective is that each of the pharmacological treatments in the existing literature acts directly on an element of the 8 component model described above. The model provides a strong theoretical basis for all of the medications that have been used to treat PG. These findings do not "prove" the model but are consistent with the majority of the proposed model components. Given the robust effect sizes, more work needs to be done with considerably larger samples to conclusively demonstrate the efficacy of the various drugs on the identified transmitter system targets to alleviate the various aspects of $\mathrm{PG}$.

One unrealized applied strength of the model is its potential to afford clinicians the ability to identify individualized targets for intervention. This targeting of specific psychobiological axes should enhance clinical efficacy in two complimentary ways. First, it can identify which individual might respond most strongly to a particular medication class. Second, it can suggest treatment combinations to address complimentary influences that bias decisions to favor PG. In the existing studies, single pharmacological treatments were applied to all individuals with a PG designation regardless of which component or components might require modification. Consequently the effect sizes displayed in Table 2 likely represent a lower limit of the potential for treatment were specific medications "matched" to an individual's constellation of underlying systemic biases. We are now working on coincident behavioral and electrophysiological techniques to objectively differentiate between groups of individuals whose PG may originate from atypical information processing originating with different model components.

\section{General Discussion}

We have presented an integrated model consisting of previously disparate but putatively interacting elements distributed across diverse anatomical and pharmacological pathways, arranged to approach or avoid immediately available rewards. We argue that the range of gambling behaviors can be ordered along two coordinates represented by neurobiological components of approach-avoidance responses. The severity dimension is dealt with by the discrepancy of specific ratios described in the model. The model posits that:

1. PG can result from over-focus on immediate reward or attempts to avoid anxiety, both of which impair ability to make sound decisions.

2. DA, T and Opioid elements synergistically favour the "approach-reward system"

3. 5-HT and $\mathrm{C}$ function to oppose the approach axis, favouring either cognitive appraisal of potential long-term costs $(5-\mathrm{HT})$ or inhibition via anxiety/fear based emotional avoidance $(\mathrm{C})$.

4. A modest rise in NE during gambling tasks promotes the "avoidance response" whereas very high levels of NE can lead to poor DM.

5. GABA functions in performance monitoring and curbs impulsive behavior.

6. Glutaminergic activity is involved in associated learning between stimuli and behaviors linked to PG; their activity is linked to DA and potentially other reward pathways. 
Despite the impressive but fragmented corpus of knowledge existent in the PG literature, the model is still open because there are no experimental studies that have concurrently examined this set of related hypotheses at various levels of psychobiological organization. Such a study would require a large sample of problem gamblers varying in terms of: (a) severity of PG, (b) preferred type of gamble, (c) co-morbidities with other forms of impulsive and compulsive psychopathologies, and (d) measurement of the putative psychobiological components. Such a study is necessary to evaluate the model and its putative members as an interacting system as opposed to studying components in isolation. We argue that a "systems approach" is necessary for two primary reasons. First, studying a complex system, one component at a time, results in "tail chasing". Second, sampling variation can result in different proportions of individuals showing PG for disparate reasons in different samples. We therefore see this model not as a finished product but as a call for systematic research. Nevertheless, this model has much to offer in terms of initial explanatory power and to direct its empirical support or refutation.

The possibility of identical clinical outcomes, in this case the development and persistence of PG, resulting from disparate systemic anomalies can be illustrated within the proposed model (Fig. 2). In the immediate "exposure stage", the individual is confronted by the (rewarding) opportunity to gamble. Excessive DA recruitment could overwhelm a "normally responsive" 5-HT system. Alternately, a typical DA recruitment would be un-tethered by a deficient 5-HT response. The model sees this DA/5-HT nexus as the initial decision point when failing adequate inhibition the individual cannot access the cognitive system to evaluate potential long- and short-term consequences and arrive at a sound decision. At this first stage then, PG could result from rapid and powerful DA recruitment or a slow and weak 5-HT response.

The second stage of the model is where stress signaling associated with NE gives way to C, which may impair DM by divergent pathways. A "hypo-stress-C response" would conceivably result in insufficient signaling of threat leading to an "impulsive choice." Paradoxically, an overly responsive NE or C system would lead to a similar DM outcome because of the cognitive disorganization intrinsic to stress and a momentary inability to effectively think one's way through a problem. Relationships between the components of the model and DM soundness are likely non-linear. This would explain discrepant finding as with psychopaths where early stressful experiences along with genetic susceptibility could lead to deregulation of the $\mathrm{C}$-stress response. The same argument could apply to all of the model's components. A moderate rise in T would be optimal to maintain motivation, but excessive $\mathrm{T}$ "priming" could restrict attentional focus to the immediate reward.

In the last stage of the model, we postulate that the ease with which DA and endorphins facilitate each other determines the extent of PG. We posit that extreme facilitation results in the orgasmic-like rush experienced by those addicted to gambling. It is not difficult to imagine why experiencing that rush would more powerfully place gambling at the center of one's existence. Gamblers with lower thresholds for eliciting the rush could make poor decisions when primed by gambling paraphernalia due to DA recruitment, but be relatively unaffected when the hypothesized model is not activated by the immediate environment. As illustrated by the Fig. 2, we propose that all levels of the system can interact, necessitating conjoint measurement of all model components to avoid seemingly discrepant results that really speak to sampling variation with PG emanating from different components of the model in different studies.

We suggest that overt behavior represents a choice among a very large number of potentially different responses to situational cues. At the neural level, this is accomplished by maintaining regulatory inhibition over the vast majority of potential informational 
pathways while disinhibiting select combinations of stored information manifested as particular behaviors. Maintaining inhibition of the majority of informational options is necessary if chaotic behaviour is to be avoided. Only the small subset of potential information deemed most relevant to the individual is disinhibited, allowing behaviour to be organized toward some purpose. Consequently, we have a relatively small number of major executive systems to regulate activation (i.e., temporally limited disinhibition) of relevant informational streams that will be expressed as overt behaviour. This general framework can be used to model the spectrum of gambling behaviors, by classifying gambling behaviors initiated to (a) reduce negative emotional or motivational states and (b) those focused on achieving positive motivational or emotional states. This we believe is essentially compatible with the various classifications of the spectrum of PG variants described above. We present a model that seeks to integrate this approach-avoidance typology with what is known in the neurobiology PG and DM literatures. We base the model on evidence across different levels of organization including personality, neuropsychology, functional neuroimaging, neuropharmacology, neuroendocrinology and genetics because of our position that strong contributions to information processing are contributed to and are consequently measurable at all of these levels providing a more tightly woven appreciation for the processes underlying these behavioural descriptions. This paper is not a comprehensive literature review of the neurobiology of problem gambling literature but presentation of a multi-component model. Comprehensive reviews of the PG neurobiology literature have recently been provided by Potenza et al. (2008, 2009).

The model is not regarded as established but principally as a conceptual basis for future research. We believe that additional elements will be found and perhaps some of our included elements may be found to be secondary to primary components of decision making. However, we believe that there is much utility to be gained by considering the coordinated operation of these components rather than more extended studies of the isolated components since empirical cases for their contributions have been made and empirical discrepancies will not lead to resolution of paradoxical findings. We argue below that this model does account for the negative findings occasionally reported in methodologically sound, but individually focused studies.

Additionally, the model has direct clinical relevance to assessing and treating PG. At the psychological level, it would appear that people indulge in PG for two basic reasons: they are drawn by the positive experience linked to winning or to overcome anxiety. The model suggests that these forms be differentiated before intervention is initiated. It makes little sense to treat a reward-focused individual by attempting to lessen his or her anxiety levels. It makes equally little sense to treat an individual seeking to escape anxiety by damping his or her reward system. We further propose that these two types of problem gamblers (designated as Type A and Type B) could be better treated optimally by training the Type A gambler to stop and consider the long-term consequences of a decision, aided initially by either DA antagonists or 5-HT agonists. We note that 5-HT agonists appear to lower T levels in sex offender samples (Adekunle et al. 2006). It may be the joint effects of SSRIs on 5-HT and T that results in effective treatment for these individuals. According to this reasoning, Type B individuals would be best served by treatment for anxiety that could combine psychotherapeutic and pharmacological components on a case by case basis. We suspect that the more severe and intransigent cases involve those seeking the rush (Type A problem gamblers), as they are not constrained by anxiety resulting form "real life consequences" of their PG.

Practically, clinicians working with PG sufferers are often at a loss to explain why, after a course of cognitive (or other) therapy, the patient appears to know all of the "right 
answers" but then relapses the next time he or she passes by a casino or a poker game. The model suggests that interviews in the clinician's office are akin to cognitive-executive tasks such as the Wisconsin Card Sorting Test, where problem gamblers often show little if any deficits (Cavedini et al. 2002). In fact, many afflicted problem gamblers are highly intelligent and otherwise capable and responsible individuals. However, the "motivational priming stimulus" is absent in the clinician's office; the office is represented by the Wisconsin Card Sorting Test. However, the community with all of its motivational pitfalls is better reflected by the motivationally salient IGT. Implications of this model for other unsound motivationally based behaviours are the subject of an upcoming paper.

Other similar models exist, most notably in the area of addictions to substances. Correspondences between PG and substance-induced addictions have been noted by different authors (Olausson et al. 2007; Petry and Oncken 2002; Cunningham-Williams et al. 2007), affording relevance of substance abuse research to PG. Our more detailed model is consistent with findings by Olausson et al. (2007) in monkeys suggesting that impairments in DM following addiction to psychostimulants is due to a combination of what they refer to as cognitive deficits attributable to the OFC as well as dysregulation of motivational impulses. We attribute the loss of cognitive control to the "short-circuiting" of the serotonergic brake by the DA reward focus. Activation of this inhibitory serotonergic mechanism is the pharmacological prerequisite for cognitive processing in our model. Kalivas and Volkow (2005) argue that addictions reflect an overwhelming motivational drive relative to modest inhibitory control, precluding effective cognitive control. Their psychobiological model, similar to ours, ascribes initiation of reinforcement choice to VTA DA but the end point is attributed to glutamate in the nucleus accumbens. Their paper notes differences between the reinforcing "pleasure" experience itself associated with striatal DA and the experience of cravings associated with activation in the OFC. Volkow et al. (2007) provide evidence for reductions in D2 OFC receptors in detoxified alcoholics accompanied by reduced local OFC metabolism. This is coupled with reduced D2 density and activity in the cingulate gyrus that is part of the inhibitory circuit for nucleus accumbens activity. Up-regulation of D2 in the Nucleus accumbens via Adenovirus migration of the D2 Receptor (D2R) into the Nucleus accumbens of rats trained to self-administer cocaine results in decreased self-administration of cocaine until D2R levels are returned to normal, reinforcing the cocaine administration role of D2 in the Nucleus accumbens (Thanos et al. 2008). From a neuroanatomical perspective, Franklin et al. (2002) found a decrease in gray (but not white) matter in cocaine abusers relative to controls in ventromedial, orbitofrontal, anterior cingulate, anteroventral insular and superior temporal cortices, ranging from $5 \%$ to $11 \%$ of volume. These authors note that the aforementioned areas have been implicated in DM, behavioural inhibition, and assignment of emotional significance to previously neutral environmental stimuli, all of which are subject to compromise in cocaine abusers. However, these researchers do not distinguish between emotional and motivational systems as our model does. Consistent with our model, this distinction has recently been explicitly identified within DM contexts by Terburg et al. (2009) who also speaks of the T/C ratio as critical in determining individual differences in approach/avoidance tendencies.

We note that the transmitter systems identified by Volkow are included in our proposed model; but Volkow's model does not make specific reference to 5-HT, NE, C or opioids that have all been shown to influence DM as described above. Our model also distinguishes between phases of DM, and their associated psychological/information processing roles. Consequently, we see Volkow's and Childress' work as generally compatible with but not equivalent to our hypothesized model, with both definite overlap but sufficient discrepancies to distinguish between them. 
Perhaps the major conceptual difference between our model and Volkow's model is that hers is a model of addictions implicitly assuming an underlying dichotomous pathology model, while ours is a general model of DM in motivational contexts that applies dimensionally across a spectrum ranging from PG (and perhaps other addictions) at the "hyper-motivated" end to "hypo-motivated" conditions such as Avoidant Personality Disorder at the other extreme. These clinical entities can be represented as extreme values in competing approach and avoidance systems. Indeed, reversing the values of elements in the proposed model can account for these divergent problem behaviours; a new "local theory" is not necessary.

We note that some specific reports (e.g., Fong et al. 2008; McElroy et al. 2008; SaizRuiz et al. 2005; Grant et al. 2003; Blanco et al. 2002) fail to confirm the roles of various components of the model. However, we contend that the model predicts that the different PG types identified by the various scholars noted above represent dysfunction of various components of the model that subsequently translates into dysregulation of the corresponding behavioural function. For example, slowly responding 5-HT systems, especially when coupled with hyper-responsive DA systems, will foster a "hyper-reward focused" PG type. Similar arguments can be made for an extreme over-focus on gambling, if there is especially tight coupling between the DA and Opioid receptor function, likely in the VTA-NAcc tract. Alternately, an unfavorably high DA/5-HT ratio could be compensated for by a highly reactive NE/Cortisol stress/anxiety system that might occur in individuals with anxiety-prone personalities.

This complex causal model has clear relevance for inconsistent findings in the literature. If participants in a given study overwhelmingly have the high DA/low 5-HT pattern but the study examines the reactivity of the NE/C system, it could be that the NE/C components perform completely adequately but will be dismissed as a component of the entire system because the PG mechanism affecting the majority of the studied participants is reflected by the DA/5-HT ratio. This underscores the necessity for first determining the particular psychological purpose that PG/P Addiction/Pathological Gambling fulfils for the each individual (e.g., reduction of anxiety, or increase in pleasure) and then using that typology as a grouping variable or covariate in analysis of resultant neuropsychological or physiological data.

One promising avenue of research to test the proposed model is to empirically assess whether DSM criteria for PG are appropriately associated with the various model components. Under the DSM-5, PG has been reclassified under "Addiction and Related Disorders" and a diagnosis of PG is warranted when an individuals presents at least 5 of the following 9 symptoms (in the absence of a Manic Episode):

1. Is preoccupied with gambling (e.g., preoccupied with reliving past gambling experiences, handicapping or planning the next venture, or thinking of ways to get money with which to gamble

2. Needs to gamble with increasing amounts of money in order to achieve the desired excitement

3. Has repeated unsuccessful efforts to control, cut back, or stop gambling

4. Is restless or irritable when attempting to cut down or stop gambling

5. Gambles as a way of escaping from problems or of relieving a dysphoric mood (e.g., feelings of helplessness, guilt, anxiety, depression)

6. After losing money gambling, often returns another day to get even ("chasing" one's losses) 
7. Lies to family members, therapist, or others to conceal the extent of involvement with gambling

8. Has jeopardized or lost a significant relationship, job, or educational or career opportunity because of gambling

9. Relies on other to provide money to relieve a desperate financial situation caused by gambling

Hypothetically, on might speculate on relationships between these diagnostic criteria and selected model components with the obvious need to empirically support or refute these associations. Hypothetically, preoccupation with PG (Criterion 1) may reflect an overwhelming immediate (DA reward) focus. Diminishing subjective returns from PG (Criterion 2) mirrors tolerance common to addictions in general and may relate to habituation in the reward system. Irritability and restlessness resulting from "gambling withdrawal" may result from a rebound effect of $\mathrm{T}$ in the context of inadequate inhibitory GABA or 5-HT. The momentary elevation of DA, T and Opioids may serve as the endogenous but temporary mood altering activity achieved by escape from problems (Criterion 5) that momentarily relieves stress, generating short-lived secondary negative reinforcement. Chasing (Criterion 6), concealing from significant others (Criterion 7), significant personal loss (Criterion 8) and financial reliance on others (Criterion 9) could all represent differing contexts demonstrating the short-circuiting of realistic thinking in the face of a need for reward salvation despite the concrete knowledge that the odds have not changed of the casino/slots winning. From the research perspective, it is important to determine whether different of these symptoms cluster together, whether the clusters appear to reflect any of the model components more than others, whether individuals with PG hitting putative clusters share alleles specific to the associated transmitters and whether they show executive function deficits logically connected to their particular symptom cluster. Such a research program would not only provide additional confirmation of the model but would also provide insight into the DSM criteria and potentially provide treatment guidelines based on the various criteria pathological gamblers experience.

The proposed model also has relevance to the research initiatives of the National Institute of Health (NIH) in the U.S. The NIH has adopted a forward-looking direction to develop a novel, observable and dimensional classification system for psychopathology closely linking with variations from typical underlying neurobiology (http://www.nimh. nih.gov/research-funding/rdoc.shtml). The NIH initiative seeks to link behavioral processes through immediate endogenous factors altering neuronal function to the longer term epigenetic and genetic constraints imposed by genes. The basic information generated by this effort is to be translated into training and practice by the Division of Developmental Translational Research (DDTR) as soon as developmentally possible. Innovative interventions for adults will cross pharmacological and behavioural lines. The Division of Services and Interventions Research (DIRS) will evaluate treatment effectiveness. Encouragingly, the Division of Intramural Research Program will oversee efforts to plot dimensions of normal to atypical brain function as related to psychopathology. More specifically, future researchers will be expected to identify and address multilevel components of cognition, hyper-arousal, negative emotionality and stress, motivation, social phobias and regulation.

The proposed model for PG adheres to these progressive tenets and adds a context for integrating them so that the model is greater than the sum of its parts. DA acts to bias DM to favor PG with high levels representing excessive short term motivation. A responsive 5-HT system affords a greater likelihood that an individual will resist stop and employ 
cognition to inhibit motivational impulses favoring immediate gratification. The tendency to act for the immediate goal is augmented by high $\mathrm{T}$ levels that arouse and activate rather than slow the system. Negative emotionality contributes to stress and hyper-arousal associated with the NE and C components of the model. The opioid system coupled with DA leads to extreme reward/motivational states rendering effective regulation and gratification avoidance more difficult. The negative emotion, anxiety, with multiple manifestations including social phobias may be instrumental in some individuals seeking and

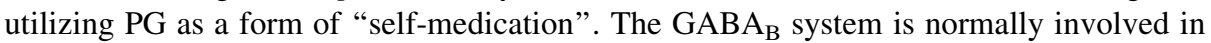
limiting excessive and inappropriate anxiety and within the model appears deficient for that task. Glutamate, as discussed here, may influence DM by associating stimuli and behavioral responses with the DA reward experience in the NAcc. The documented interactions between the model components (i.e., DA and 5-HT, 5-HT and T, GABA $\mathrm{B}_{\mathrm{B}}$ and GLU, GLU and $\mathrm{DA}, \mathrm{GABA}_{\mathrm{B}}$ and $\mathrm{NE} / \mathrm{C}$ ) and their psychological manifestations underscore the need for research to integrate understanding of these interrelationships to identify grounded subtypes of PG, develop optimal experiential and pharmacological interventions and monitor their effectiveness. We see the model as encompassing the broad intent of the NIH initiatives and hope that it will prove useful for researchers in PG to organize proposals in concert with NIH's progressive goals.

In closing, we believe that the presented systemic model is consistent with the existing literature in the field of PG studies at multiple levels of organization. In addition to providing a tentative explanatory model for PG and possible sub-types, it is our hope to initiate research to support or invalidate its components, test whether additional components are necessary to explain unaccounted variance, and spur applied research into why some interventions are more or less beneficial to subtypes of problem gamblers.

Acknowledgments The authors wish to thank my colleagues (alphabetically) Drs. Robert Ax, Tony George, Gabriela Ilie, Diana Jovanovski, David Teplin, Sidney Topiol, and Konstantine Zakzanis for helpful comments on this manuscript and Shayna Nussbaum for providing help with the literature review. Funding for this project and the Open Choice option was generously provided by the Ontario Problem Gambling Research Centre, Guelph, Ontario, Canada.

Open Access This article is distributed under the terms of the Creative Commons Attribution Noncommercial License which permits any noncommercial use, distribution, and reproduction in any medium, provided the original author(s) and source are credited.

\section{References}

Abler, B., Hahlbrock, R., Unrath, A., Groen, G., \& Kassubek, J. (2009). At-risk for pathological gambling: Imaging neural reward processing under chronic dopamine agonists. Brain, 132(9), 2396-2402.

Adekunle, A. G., Fedoroff, P., Firestone, P., Bradford, J., \& Curry, S. (2006). Serum testosterone, luteinizing hormone, hostility and recidivism in convicted sex offenders. Biological Psychiatry, 59, 128S.

Alexander, G. E., DeLong, M., \& Strick, P. E. (1986). Parallel organization of functionally segregated circuits linking basal ganglia and cortex. Annual Review of Neuroscience, 9, 357-381.

Alexander, J. K., Hillier, A., Smith, R. M., Tivarus, M. E., \& Bersdarf, D. Q. (2007). Beta-adrenergic modulation of cognitive flexibility during stress. Journal of Cognitive Neuroscience, 19, 468-478.

APA (1994). Diagnostic and statistical manual of mental disorders (4th ed.). Washington, D.C.: American Psychiatric Association.

Assadi, S. M., Yucel, M., \& Pantelis, C. (2009). Dopamine modulates neural networks involved in effortbased decision-making. Neuroscience and Biobehavioral Reviews, 33, 383-393.

Bass, S. L. S., \& Nussbaum, D. (2010). Decision-making and aggression in forensic psychiatric inpatients. Criminal Justice and Behavior, 37, 365-383.

Bechara, A., Damasio, H., \& Damasio, A. R. (2001). Manipulation of dopamine and serotonin cause different effects on covert and overt decision-making. Society for Neuroscience Abstracts, 27. 
Bechara, A., Damasio, A. R., Damasio, H., \& Anderson, S. W. (1994). Insensitivity to future consequences following damage to human prefrontal cortex. Cognition, 50, 7-15.

Bechara, A., Dolan, S., \& Hindes, A. (2002). Decision-making and addiction (Part II): Myopia for the future or hypersensitivity to reward? Neuropsychologia, 40, 1690-1705.

Bergh, C., Eklund, T., Sodersten, P., \& Nordin, C. (1997). Altered dopamine function in pathological gambling. Psychological Medicine, 27, 473-475.

Black, D. W., Shaw, M. C., \& Allen, J. (2008). Extended release carbamazepine the treatment of pathological gambling: An open-label study. Progress in Neuro-Psychopharmacology and Biological Psychiatry, 32(5), 1191-1194.

Blanco, C., Báñez, A., Blanco-Jerez, C. R., Baca-Garcia, E., \& Sáiz-Ruiz, J. (2001). Plasma testosterone and pathological gambling. Psychiatry Research, 105, 117-121.

Blanco, C., Orensanz-Munoz, L., Blanco-Jerez, C., \& Saiz-Ruiz, J. (1996). Pathological gambling and platelet MAO activity: A psychobiological study. American Journal of Psychiatry, 153, 119-121.

Blanco, C., Petkova, E., Ibanez, A., \& Saiz-Ruiz, J. (2002). A pilot placebo-controlled study of fluvoxamine for pathological gambling. Annals of Clinical Psychiatry, 14, 9-15.

Blaszczynski, A. P., Winter, S. W., \& McConaghy, N. (1986). Plasma endorphin levels in pathological gambling. Journal of Gambling Behavior, 2, 3-14.

Blazszczynski, A., \& Nower, L. (2002). A pathways model of problem and pathological gambling. Addiction, 97, 487-499.

Blazszczynski, A., \& Steel, Z. (1998). Personality disorders among pathological gamblers. Journal of Gambling Studies, 14, 51-75.

Blazszczynski, A., Steel, Z., \& McConaghy, N. (1997). Impulsivity in problem gamblers: The antisocial impulsivist. Addictions, 92, 75-87.

Brebner, K., Childress, A. R., \& Roberts, D. C. S. (2002). A potential role for GABA $_{B}$ agonists in the treatment of psychostimulant addiction. Alcohol and Alcoholism, 37, 478-484.

Brunner, D., \& Hen, R. (1997). Insights into the neurobiology of impulsive behavior from serotonin receptor knockout mice. Annals of the New York Academy of Sciences, 836, 81-105.

Capraro, R. M. (2004). Statistical significance, effect size reporting, and confidence intervals: Best reporting strategies. Journal for Research in Mathematics Education, 35, 57-62.

Carrasco, J. L., Saiz-Ruiz, J., Hollander, E., Cesar, J., \& Lopez-Ibor, J. J., Jr. (1994). Low platelet monoamine oxidase activity in pathological gambling. Acta Psychiatrica et Neurologica Scandinavica, 90, 427-431.

Cavedini, P., Riboldi, G., Keller, R., D’Annucci, A., \& Bellodi, L. (2002). Frontal lobe dysfunction in pathological gambling patients. Biological Psychiatry, 51(4), 334-341.

Comings, D. E. (1998). Why different rules are required for polygenic inheritance: Lessons from studies of the DRD2 gene. Alcohol, 16, 61-70.

Comings, D. E., Dietz, G., Johnson, J. P., \& MacMurray, J. P. (1999). Association of the enkephalinase gene with low amplitude P300 waves. Neuroreport: For Rapid Communication of Neuroscience Research, 10, 2283-2285.

Comings, D. E., Gade-Andavolu, R., Gonzalez, N., Wu, S., Muhleman, D., Chen, C., et al. (2001). The addictive effects of neurotransmitter genes in pathological gambling. Clinical Genetics, 60, 107-116.

Comings, D. E., Muhleman, D., \& Gysin, R. (1996). Dopamine D-sub-2 receptor (DRD2) gene and susceptibility to posttraumatic stress disorder: A study and replication. Biological Psychiatry, 40, 368-372.

Cox, B. J., Yu, N., Afifi, A. O., \& Ladouceur, R. (2005). A national survey of gambling problems in Canada. Canadian Journal of Psychiatry, 50, 213-217.

Cunningham-Williams, R. M., Abdallah, A. B., Callahan, C., \& Cottler, L. (2007). Problem gambling and violence among community-recruited female substance abusers. Psychological of Addictive Behaviors, 21(2), 239-243.

Da Silva Lobo, D. S., Vallada, H. P., Knight, J., Martins, S. S., Tavares, H., Gentil, V., et al. (2007). Dopamine genes and pathological gambling in discordant sib-pairs. Journal of Gambling Studies, 23, 421-433.

Dabbs, J. M., \& Dabbs, M. G. (2000). Heroes, rogues, and lovers. Testosterone and behavior. New York: McGraw Hill.

Dannon, P. N., Lowengrub, K., Gonopolski, Y., Musin, E., \& Kotler, M. (2005a). Topiramate versus fluvoxamine in the treatment of pathological gambling: A randomized, blind-rater comparison study. Clinical Neuropharmacology, 28(1), 6-10.

Dannon, P. N., Lowengrub, K., Musin, E., Gonopolski, Y., \& Kotler, M. (2005b). Sustained-release bupropion versus naltrexone in the treatment of pathological gambling: A preliminary blind-rater study. Journal of Clinical Psychopharmacology, 25(6), 593-596. 
Daw, N. D., Kakade, S., \& Dayan, P. (2002). Opponent interactions between serotonin and dopamine. Neural Networks, 15, 603-616.

de Castro, P. I., Ibanez, A., Saiz-Ruiz, J., \& Fernandez-Piqueras, J. (2001). Concurrent positive association between pathological gambling and functional DNA polymorphisms at the MAO-A and the 5-HT transporter genes. Molecular Psychiatry, 7, 927-928.

DeCaria, C. M., Hollander, E., Grossman, R., Wong, C. M., Mosovich, S. A., \& Cherkasky, S. (1996). Diagnosis, neurobiology, and treatment of pathological gambling. Journal of Clinical Psychiatry, 57, 80-83.

DeCaria, C. M., Hollander, E., Nora, R., Stein, D., Simeon, D., \& Cohen, I. (1997). Gambling: Biological/ genetic, treatment, government, and gambling concerns: Neurobiology and treatment of pathological gambling. Paper presented at the American Psychiatric Association Annual Meeting, San Diego, CA.

Devilly, G. J. (2005). ClinTools Software for Windows. Version 4 (Computer Program). Swinburne University, Australia: The Centre for Neuropsychology.

Durlak, J. A. (1995). Understanding meta-analysis. In L. G. Grimm \& P. R. Yarnold (Eds.), Reading and understanding multivariate statistics. Washington, D.C.: APA.

Elliot, A. J., Faler, J., McGregor, H. A., Campbell, W. K., Sedikides, C., \& Harackiewicz, J. M. (2000). Competence valuation as a strategic intrinsic motivation process. Personality and Social Psychology Bulletin, 26, 780-794.

Engel, G. L. (1977). The need for a new medical model: A challenge for biomedicine. Science, 196, 129-136.

Fahlke, C., Lorenz, J. G., Long, J., Champouz, M., Suomi, S. J., \& Higley, J. D. (2000). Rearing experiences and stress-induced plasma cortisol as early risk factors for excessive alcohol consumption in nonhuman primates. Alcoholism, Clinical and Experimental Research, 24, 644-650.

Fennema, H., \& van Assen, M. (1998). Measuring the utility of losses by means of the tradeoff method. Journal of Risk and Uncertainty, 17, 277-295.

Fong, T., Kalechstein, A., Bernhard, B., et al. (2008). A double-blind, placebo controlled trial of olanzapine for the treatment of video poker pathological gamblers. Pharmacology, Biochemistry and Behavior, 89, 298-303.

Franklin, T. R., Acton, P. D., Maldijian, J. A., Gray, J. D., Croft, J. R., Dackis, C. A., et al. (2002). Decreased gray matter concentration in the insular, orbitofrontal, cingulate, temporal cortices of cocaine patients. Biological Psychiatry, 51, 134-142.

Ghebrial, M. E. (2006). Hormone-behavior correlates among male and female psychopathic participants: Relationship to Gray's model of behavioural inhibition and activation systems. Dissertation Abstracts International: Section B: The Sciences and Engineering, 66(12-B), 6921.

Gianoulakis, C., De Waele, J., \& Thavundayil, J. (1996). Implication of the endogenous opioid system in excessive ethanol consumption. Alcohol, 13, 19-23.

Giladi, N., Weitzman, N., Schreiber, S., Shabtai, H., \& Peretz, C. (2007). New onset heightened interest or drive for gambling, shopping, eating or sexual activity in patients with Parkinson's disease: The role of dopamine agonist treatment and age at motor symptoms onset. Journal of Psychopharmacology, 21, 501-506.

Goudriaan, A. E., Oosterlaan, J., de Beurs, E., \& Van den Brink, W. (2004). Pathological gambling: A comprehensive review of biobehavioural findings. Neuroscience \& Behavioral Reviews, 28, 123-141.

Goudriaan, A. E., Oosterlaan, J., de Beurs, E., \& van den Brink, W. (2005). Decision making in pathological gambling: A comparison between pathological gamblers, alcohol dependents, persons with Tourette syndrome, and normal controls. Cognitive Brain Research. Special Issue: Multiple Perspectives on Decision Making, 23, 137-151.

Grant, J. E., \& Kim, S. W. (2006). Medication management of pathological gambling. Minnesota Medicine, 89, 44-48.

Grant, J. E., Kim, S. W., \& Odlaug, B. L. (2007). N-acetyl cysteine, a glutamate-modulating agent, in the treatment of pathological gambling: A pilot study. Biological Psychiatry, 62, 652-657.

Grant, J. E., Kim, S. W., Potenza, M. N., et al. (2003). Paroxetine treatment of pathological gambling: A multi-center randomized controlled trial. International Clinical Psychopharmacology, 18, 243-249.

Grant, J. E., \& Potenza, M. N. (2006). Escitalopram treatment of pathological gambling with co-occurring anxiety: An open-label pilot study with double-blind continuation. International Clinical Psychopharmacology, 21(4), 203-209.

Grant, J. E., Potenza, M. N., Hollander, E., Cunningham-Williams, R., Nurminen, T., Smits, G., \& Kallio, A. (2006). Multicenter investigation of the opiod antagonist nalmefene in the treatment of pathological gambling. American Journal of Psychiatry, 163, 303-312.

Griffiths, M. D., \& Delfabbro, P. H. (2001). The biopsychosocial approach to the study of gambling. Gambling: The Electronic Journal of Gambling Issues, 5, 1-33. 
Hanson, R. K., Bourgnon, G., Helmus, L., \& Hodgson, S. (2009). The principles of effective correctional treatment also apply to sexual offenders: A meta-analysis. Criminal Justice and Behavior, 36, 865-891.

Hollander, E., DeCaria, C. M., Finkell, J. N., Begaz, T., Wong, C. M., \& Cartwright, C. A. (2000). Randomized double blind fluvoxamine/placebo crossover trial in pathological gambling. Biological Psychiatry, 47, 813-817.

Hollander, E., DeCaria, C. M., Mari, E., Wong, C. M., Mosovich, S., Grossman, R., et al. (1998). Short-term single-blind fluvoxamine treatment of pathological gambling. American Journal of Psychiatry, 155, 1781-1783.

Holman, A. J. (2009). Impulse control disorder behaviors associated with pramipexole used to treat fibromyalgia. Journal of Gambling Studies, 25(3), 425-431.

Ibanez, A., de Castro, P., Fernandez-Piqueras, J., \& Saiz-Ruiz, J. (2000). Association between the lowfunctional MAO-A gene promoter and pathological gambling. Versailles (France): Eighth World Congress on Psychiatric Genetics.

Ibanez, A., de Castro, P. I., Fernandez-Piqueras, J., \& Saiz-Ruiz, J. (2001).Tyrosine hydroxylase gene and pathological gambling: An association study. 7th World Congress of Psychiatric Genetics, Monterey, CA(USA), p. 272.

Johansson, A., Grant, J., Kim, S. W., Odlaug, B. L., \& Götestam, K. G. (2009). Risk factors for problematic gambling: A critical literature review. Journal of Gambling Studies, 25(1), 67-92.

Kalivas, P. W. (2009). The glutamate homeostasis theory of addiction. Nature Neuroscience Reviews, 10, 561-572.

Kalivas, P. W., \& Volkow, N. D. (2005). The neural basis of addiction: A pathology of motivation and choice. American Journal of Psychiatry, 162, 1403-1413.

Kaufman, K. R., Kugler, S. L., \& Sachdeo, R. C. (2002). Tiagabine in the management of postencephalitic epilepsy and impulse control disorder. Epilepsy \& Behavior, 3, 190-194.

Kerfoot, E. C., Chattillion, E. A., \& Williams, C. L. (2008). Functional interactions between the nucleus tractus solitaries (NTS) and nucleus accumbens shell in modulating memory for arousing experiences. Neurobiology of Learning and Memory, 89, 47-60.

Kessler, R. C., Hwang, I., LaBrie, R., Petukhova, M., Sampson, N. A., Winters, K. C., et al. (2008). DSM-IV pathological gambling in the National Comorbidity Survey Replication. Psychological Medicine, 38, 1351-1360.

Kim, S. W., \& Grant, J. E. (2001). An open naltrexone treatment study in pathological gambling disorder. International Clinical Psychopharmacology, 16, 285-289.

Kim, S. W., Grant, J. E., Adson, D. E., \& Shin, Y. C. (2001). Double-blind naltrexone and placebo comparison study in the treatment of pathological gambling. Biological Psychiatry, 49, 914-921.

Kim, S. W., Grant, J. E., Adson, D. E., Shin, Y. C., \& Zaninelli, R. (2002). A double-blind placebocontrolled study of the efficacy and safety of paroxetine in the treatment of pathological gambling. Journal of Clinical Psychiatry, 63, 501-507.

Kreek, M. J., Nielsen, D. A., Butelman, E. R., \& LaForge, K. S. (2005). Genetic influences on impulsivity, risk taking, stress responsivity and vulnerability to drug abuse and addiction. Nature Neuroscience, 8 , 1450-1457.

Krystal, J. H., D’Souza, C., Mathalon, D., Perry, E., Aysenil, B., \& Hoffman, R. (2003). NMDA receptor antagonist effects, cortical glutamatergic function, and schizophrenia: Toward a paradigm shift in medication development. Psychopharmacology, 169, 215.

Lee, T. K., La Brie, R. A., Grant, J. E., Kim, S. W., \& Shaffer, H. J. (2008). The structure of pathological gambling among Korean gamblers: A cluster and factor analysis of clinical and demographic characteristics. International Journal of Mental Health Addiction, 6, 551-563.

McClure, S. M., Laibson, D. L., Loewnstein, G., \& Cohen, J. D. (2004). Separate neural systems value immediate and delayed monetary reward. Science, 306, 503-507.

McElroy, S., Nelson, E., Welge, J., et al. (2008). Olanzapine in the treatment of pathological gambling: A negative randomized placebo-controlled trial. Journal of Clinical Psychiatry, 69, 433-440.

Meyer, G., Hauffa, B. P., Schedlowski, M., Pawlak, C., Stadler, M. A., \& Exton, M. S. (2000). Biological Psychiatry, 48, 948-953.

Meyer, G., Schwertfeger, J., Exton, M. S., Janssen, O. E., Knapp, W., Stadler, M. A., Schedlowski, M., \& Kruger, T. H. C. (2004). Neuroendocrine response to casino gambling in problem gamblers. Psychoneuroendocrinology, 29, 1272-1280.

Moreno, I., Saiz-Ruiz, J., \& Lopez Ibor, J. J. (1991). Serotonin and gambling dependence. Human Psychopharmacology, 6, S9-S12.

Nelson, S. E., Gebauer, L., LaBrie, R. A., \& Shaffer, H. J. (2009). Gambling problems symptom patterns and stability across individual and timeframe. Psychology of Addictive Behaviors, 23(3), 523-533. 
Nordin, C., \& Eklundh, T. (1999). CSF 5-HIAA disposition in pathologic male gamblers. CNS Spectrums, 4, $25-33$.

Nordin, C., \& Sjodin, I. (2006). CSF monoamine patterns in pathological gamblers and healthy controls. Journal of Psychiatric Research, 40, 454-459.

Nower, L., \& Blazszczynski, A. (2006). Impulsivity and pathological gambling: A descriptive model. International Gambling Studies, 6(1), 61-75.

Olausson, P., Jentsch, J. D., Krueger, D. D., Tronson, N. C., Nairn, A. C., \& Taylor, J. R. (2007). Orbitofrontal cortex and cognitive-motivational impairments in psychostimulant addiction. Annals of the New York Academy of Sciences, 1121, 610-638.

Pallanti, S., Baldini Rossi, N., Sood, E., \& Hollander, E. (2002a). Nefazodone treatment of pathological gambling: A prospective open-label controlled trial. Journal of Clinical Psychiatry, 63, 1034-1039.

Pallanti, S., Bernardi, S., Quercioli, L., DeCaria, C., \& Hollander, E. (2006). Serotonin dysfunction in pathological gamblers: Increased prolactin response to oral m-CPP versus placebo. CNS Spectrums, 11, 956-964.

Pallanti, S., Quercioli, L., Sood, E., \& Hollander, E. (2002b). Lithium and valproate treatment of pathological gambling: A randomized single-blind study. Journal of Clinical Psychiatry, 63(7), 559-564.

Perez, D. C. I., Ibanez, A., Saiz-Ruiz, J., \& Fernandez-Piqueras, J. (1999). Genetic contribution to pathological gambling: Possible association between a functional DNA polymorphism at the serotonin transporter gene (5-HTT) and affected men. Pharmacogenetics, 9, 397-400.

Petry, N. M. (2001). Substance abuse, pathological gambling, and impulsiveness. Drug and Alcohol Dependence, 63(1), 29-38.

Petry, N. M., \& Oncken, C. (2002). Cigarette smoking is associated with increased severity of gambling problems in treatment-seeking gamblers. Addiction, 97(6), 745-753.

Pirastu, R., Fais, R., Messina, M., Bini, V., Spiga, S., Falconieri, D., et al. (2006). Impaired decision-making in opiate-dependent subjects: Effect of pharmacological therapies. Drug and Alcohol Dependence, 83, $163-168$.

Potenza, M. N. (2008). The neurobiology of pathological gambling and drug addiction: An overview and new findings. Philosophical Transactions of the Royal Society B: Biological Sciences, 363, 1507.

Potenza, M. N. (2009). Non-substance and substance addictions. Addiction, 104, 1016-1017.

Potenza, M. N., Leung, H. C., Blumberg, H. P., Peterson, B. S., Fulbright, R. K., Lacadie, C. M., et al. (2003a). An fMRI Stroop task study of ventromedial prefrontal cortical function in pathological gamblers. The American Journal of Psychiatry, 160(11), 1990-1994.

Potenza, M. N., Steinberg, M. A., Skudlarski, P., Fulbright, R. K., Lacadie, C. M., Wilber, M. K., et al. (2003b). Gambling urges in pathological gambling: A functional magnetic resonance imaging study. Archives of General Psychiatry, 60, 828-836.

Reuter, J., Raedler, T., Rose, M., Hand, I., Glascher, J., \& Buchel, C. (2005). Pathological gambling is linked to reduced activation of the mesolimbic reward system. Nature Neuroscience, 8, 147-148.

Rogers, R. D., Blackshaw, A. J., Middleton, H. C., Matthews, K., Hawtin, K., Crowley, C., et al. (1999). Tryptophan depletion impairs stimulus-reward learning while methylphenidate disrupts attentional control in healthy young adults: Implications for the monoaminergic basis of impulsive behaviour. Psychopharmacology. Special Issue: Impulsivity, 146, 482-491.

Rogers, R. D., Lancaster, M., Wakeley, J., \& Bhagwagar, Z. (2004). Effects of beta-adrenoceptor blockade on components of human decision-making. Psychopharmacology, 172, 157-164.

Rompre, P. P., \& Wise, R. A. (1989). Behavioral evidence for midbrain dopamine depolarization inactivation. Brain Research, 477, 152-156.

Ronken, E., Mulder, A. H., \& Schffelmeer, A. N. M. (1993). Interacting presynaptic k-opioid and $\mathrm{GABA}_{\mathrm{A}}$ receptors modulate dopamine release from rat striatal synaptosomes. Journal of Neurochemistry, 61, $1634-1639$.

Ross, S., \& Peselow, E. (2009). The neurobiology of addictive disorders. Clinical Neuropharmacology, 32, 269-276.

Roussos, P., Giakoumaki, S. G., Pavlakis, S., \& Bitsios, P. (2008). Planning, decision-making and the COMT rs4818 polymorphism in healthy males. Neuropsychologia, 46, 757-763.

Roy, A., Adinoff, B., Roehrich, L., Lamparski, D., Custer, R., Lorenz, V., et al. (1988). Pathological gambling: A psychobiological study. Archives of General Psychiatry, 45, 369-373.

Saiz-Ruiz, J., Blanco, C., Ibanez, A., Masramon, X., Gomez, M. M., Madrigal, M., et al. (2005). Sertraline treatment of pathological gambling: A pilot study. Journal of Clinical Psychiatry, 66, $28-33$.

Scherrer, J. F., Xian, H., Kapp, J. M. K., Waterman, B., Shah, K. R., Volberg, R., et al. (2007). Association between exposure to childhood and lifetime traumatic events and lifetime traumatic pathological gambling in a twin cohort. Journal of Nervous and Mental Disease, 95, 72-78. 
Schmitt, L. H., Harrison, G. A., \& Spargo, R. M. (1998). Variation in epinephrine and cortisol excretion rates associated with behavior in an Australian Aboriginal community. American Journal of Physical Anthropology, 106, 249-253.

Sharpe, L. (2004). Patterns of autonomic arousal in imaginal situations of winning and losing in problem gambling. Journal of Gambling Studies, 20, 95-104.

Shead, N. W., \& Hodgins, D. C. (2009). Affect-regulation expectancies among gamblers. Journal of Gambling Studies, 25(3), 357-375.

Shima, K., \& Tanji, J. (1998). Role of cingulate motor area cells in voluntary movement selection based on reward. Science, 282, 5392.

Shinohara, K., Yanagisawa, A., Kagota, Y., Gomi, A., Nemoto, K., Moriya, E., et al. (1999). Physiological changes in Pachinko players; beta-endorphin, catecholamines, immune system substances and heart rate. Applied Human Science: Journal of Physiological Anthropology, 18, 37-42.

Skitch, S. A., \& Hodgins, D. C. (2004). Impulsivity, compulsivity and pathological gambling: An exploratory study of pathological gambling as an impulsivity-compulsivity spectrum disorder. International Gambling Studies, 4(2), 175-188.

Sofuoglu, M., Poling, J., Gonzalez, G., Gonsai, K., \& Kosten, T. (2006). Cocaine withdrawal symptoms predict medication response in cocaine users. American Journal of Drug and Alcohol Abuse, 32, 617-627.

Stahl, S. M. (2008). Essential psychopharmacology: Neuroscientific basis and practical applications (3rd ed.). New York: Cambridge University Press.

Steeves, T. D. L., Miyasaki, J., Zurowski, M., Lang, A. E., Pellecchia, G., Van Eimeren, T., et al. (2009). Increased striatal dopamine release in Parkinsonian patients with pathological gambling: A [11C] raclopride PET study. Brain, 132(5), 1376-1385.

Stewart, S. H., \& Zack, M. (2008). Development and psychometric evaluation of a three-dimensional Gambling Motives Questionnaire. Addiction, 103, 1110-1117.

Stewart, S. H., Zack, M., Collins, P., Klein, R., \& Fragopoulos, F. (2008). Subtyping pathological gamblers ion the basis of affective motivations for gambling: Relations to gambling problems, drinking problems, and affective motivation for drinking. Psychology of Addictive Behaviors, 22(2), 257-268.

Tanabe, J., Thompson, L., Claus, E., Dalwani, M., Hutchison, K., \& Banich, M. T. (2007). Prefrontal cortex activity is reduced in gambling and non-gambling substance users during decision-making. Human Brain Mapping, 28, 1276-1286.

Terburg, D., Mogan, B., \& van Honk, J. (2009). The testosterone-cortisol ratio: A hormonal marker for proneness to social aggression. International Journal of Law and Psychiatry, 32, 216-223.

Thanos, P. K., Michaelides, M., Umegaki, H., \& Volkow, N. D. (2008). D2R DNA transfer into the nucleus accumbens attenuates cocaine self-administration in rats. Synapse, 62, 481-486.

Thiel, A., Hilker, R., Kessler, J., Habedank, B., Herholz, K., \& Heiss, W. D. (2003). Activation of basal ganglia loops in idiopathic Parkinson's disease: A PET study. Journal of Neural Transmission, 110, 1303-1311.

Thompson, M., \& Thompson, L. (2003). The Neurofeedback book: An introduction to basic concepts in applied psychophysiology (1st ed.). Colorado: The Association for Applied Psychophysiology and Biofeedback.

Toneatto, T. (1999). Cognitive psychopathology of problem gambling. Substance Use and Misuse, 34, 1593-1604.

Topf, J. L., Yip, S. W., \& Potenza, M. N. (2009). Pathologic gambling: Biological and clinical considerations. Journal of Addiction Medicine, 3, 111-119.

Toplak, M. E., Liu, E., MacPherson, R., Toneatto, T., \& Stanovich, K. E. (2007). The reasoning skills and thinking dispositions of problem gamblers: A dual-process taxonomy. Journal of Behavioral Decision Making, 20, 103-124.

van Hank, J., Schutter, D. J. L. G., Hermans, E. J., \& Putman, P. (2003). Low cortisol levels and the balance between punishment sensitivity and reward dependency. Neuroreport, 14, 1993-1996.

van Honk, J., Schutter, D. J. L. G., Hermans, E. J., Putman, P., Tuiten, A., \& Koppeschaar, H. (2004). Testosterone shifts the balance between sensitivity for punishment and reward in healthy young women. Psychoneuroendocrinology, 29, 937-943.

Vogel-Sprott, M. (1967). Alcohol effects on human behavior under reward and punishment. Psychopharmacologia, 11, 337-344.

Vogel-Sprott, M., Easdon, C., Fillmore, M., Finn, P., \& Justus, A. (2001). Alcohol and behavioral control: Cognitive and neural mechanisms. Alcoholism, Clinical and Experimental Research, 25, 117-121.

Volkow, N. D., Wang, G. J., \& Telang, F. (2007). Profound decrease in dopamine release in striatum in detoxified alcoholics: Possible orbitofrontal involvement. Journal of Neuroscience, 27, 12700-12706. 
Weintraub, D., Siderowf, A. D., Potenza, M. N., Goveas, J., Morales, K. H., Duda, J. E., et al. (2006). Association of dopamine agonist use with impulse control disorders in Parkinson disease. Archives of Neurology, 63(7), 969-973.

Westphal, J. R. (2008). Pathological gambling: Psychiatric models. International Journal of Mental Health Addiction, 6, 602-618.

Wilkinson, L., \& Task Force on Statistical Inference. (1999). Statistical methods in psychology journals: Guidelines and explanations. American Psychologist, 54, 594-604.

Williams, R. J., West, B. L., \& Simpson, R. I. (2007). Prevention of problem gambling. In G. Smith, D. C. Hodgins, \& R. J. Williams (Eds.), Research and measurement issues in gambling studies (pp. 400-425). Burlington: Academic Press.

Winstanley, C. A., Theobald, D. E. H., Dalley, J. W., Cardinal, R. N., \& Robin, T. W. (2006). Double dissociation between serotonergic and dopaminergic modulation of medial prefrontal and orbitofrontal cortex during a test of impulsive choice. Cerebral Cortex, 16, 106-114.

Wong, D. F., Kuwabara, H., Schretlen, D. J., Bonson, K. R., Zhou, Y., Nandi, A., et al. (2006). Increased occupancy of dopamine receptors in human striatum during cue-elicited cocaine craving. Neuropsychopharmacology, 31(12), 2716-2727.

Zack, M., \& Poulos, C. X. (2004). Amphetamine primes motivation to gamble and gamblingrelated semantic networks in problem gamblers. Neuropsychopharmacology, 29, 195-207.

Zack, M., \& Poulos, C. X. (2007). A D2 antagonist enhances the rewarding and priming effects of a gambling episode in pathological gamblers. Neurospsychopharmacology, 32, 1678-1686.

Zimmerman, M., Breen, R. B., \& Posternak, M. A. (2002). An open-label study of citalopram in the treatment of pathological gambling. Journal of Clinical Psychiatry, 63, 44-48. 